\title{
Computational investigation of a large containership propulsion engine operation at slow steaming conditions
}

\author{
Cong Guan ${ }^{\mathrm{a}, 1}$, Gerasimos Theotokatos ${ }^{\mathrm{b}, 1,{ }^{*}, \text { Peilin Zhou }}{ }^{\mathrm{b}}$, Hui Chen ${ }^{\mathrm{a}}$ \\ a Key Laboratory of High Performance Ship Technology of Ministry of Education, School of Energy and \\ Power Engineering, Wuhan University of Technology, 1178 Heping Road, Wuhan 430063, China \\ b Department of Naval Architecture, Ocean \& Marine Engineering, 100 Montrose Street, \\ Glasgow G4 OLZ, UK \\ * Corresponding author. \\ 1 These authors contributed equally to this work.
}

Abstract In this paper the operation of a large containership main engine was investigated with emphasis at slow steaming conditions. A cycle mean value approach implemented in the MATLAB/Simulink environment was adopted to simulate the two-stroke marine diesel engine due to the fact that it combines simplicity with adequate prediction accuracy. For accurately representing the compressor performance when the engine operates at low loads, the extension of the compressor map at the low rotational speed region was carried out based on a non-dimensional parameters method incorporating a novel way of calculating the compressor isentropic efficiency. The compressor map extension method results were validated using a corrected similarity laws approach. The engine steady state operation for various loads was simulated and the predicted engine performance parameters were validated using shop trial measurements. Furthermore, the engine transient operation in the load region below $50 \%$ was studied and the simulation results including the compressor operating points trajectory are presented and discussed. Based on the obtained results, the influence of the activation/deactivation of the installed electric driven blowers on the engine operation was analysed.

Key words Cycle mean value engine modelling; Large containership propulsion engine; Slow steaming; Compressor performance map extension; Electric driven blower operation, Turbocharger cut-out. 


\section{Introduction}

The shipping industry faces multiple challenges in the last few years taking into account the unprecedented rise of fuel prices [1-3] and the consequential impact on ship operating cost which, in turn, affects cargo transport cost [4-6] and company competitiveness and viability. In addition, the increasing demand for shipping transport capacity from last financial crisis [7] is expected to further increase marine fuels demand and as a result the emitted $\mathrm{CO}_{2}$ emissions. Furthermore, the continuously increasing concern for greening shipping industry activities, the imposed new international and national regulations for limiting greenhouse and non-greenhouse emissions [8-10], as well as the significant reduction of chartered ship rates [11] have introduced additional burdens. Therefore, slow steaming has been rendered as a standard operating procedure in shipping industry especially for the containerships which were sailing at high speeds in the range of 20-24 knots [12]. A significant number of containership operators have even adopted the super slow steaming operating strategy [13] and consequently save considerable fuel amount and emit less gaseous emissions.

In order to achieve the more efficient and environmentally cleaner operation of their products, the engine manufacturers have developed and applied a number of measures including the introduction of the electronically controlled versions of marine diesel engines $[14,15]$, in which the camshaft that exists in traditional engine versions for adjusting the injection timing and exhaust valve opening has been replaced by computer-controlled high-pressure hydraulic systems, and waste heat recovery systems [16-18]. In addition, retrofitting packages for turbocharger units isolation, exhaust gas bypass and turbochargers with variable geometry turbines have been presented $[19,20]$ for maximizing the engine efficiency throughout the engine operating envelope, especially when the engine runs at slow steaming conditions. In addition, cylinder cut-out has also been proposed and ways for isolating a number of 
cylinders at slow steaming operation have been investigated. In consequence, more attention is needed to be paid to the understanding of engine behaviour at low engine load region.

Since the size and weight of two-stroke marine diesel engines as well as their procurement, running and experimental testing costs are enormous [21], various engine modelling techniques have been extensively used for investigating the engine steady-state performance and transient response, for testing various engine designs and for developing the engine control system. In the previously published studies [22-33], various models have been developed and applied for simulating marine engines under steady-state and transient conditions. The most commonly used ones are the zero-dimensional models [22-27] and the cycle mean value engine models (MVEM) [28-33]. The former can represent the engine working processes more accurately but they are more complex, and require a greater amount of input data and execution time. The latter are simpler and need a less amount of input data, while predicting the engine behaviour with sufficient accuracy. The basic assumption adopted in the cycle mean value models is that the air and fuel flows entering and exiting the engine cylinders are continuous. So the engine cycle averaged temporal evolution of the engine operating parameters can be calculated, whereas their in-cycle variation (per degree of crank angle) cannot be represented [33,34].

For accurately representing the engine behaviour at slow steaming conditions, the compressor characteristics at the region of very low rotational speed are required. Since the compressor performance maps provided by turbocharger manufacturers usually do not cover the region below $40 \%$ of the maximum turbocharger rotational speed [35], the extension of the compressor map must be performed. In previous studies [36-41], various ways of modelling the turbocharger compressor as well as extending the compressor performance map were described. Jensen et al. [36] used a compressor model based on the dimensionless parameters method, which is considered to be one of the most stable ways to predict 
compressor performance with adequate accuracy. Guillaume et al. [37] proposed an approach based on the turbomachinery physics for modelling the turbocharger compressor and extrapolate/interpolate the compressor map. Wayne [38] used a method based on the principles of similarity laws to extrapolate the compressor map into low speed operating region, according to which the compressibility effects were taken into account by considering varying exponent value in the similarity laws equations. Ghorbanian et al. [39], Cortes et al. [40], Yu et al. [41] applied neural networks techniques for predicting the compressor performance.

Although numerous studies have been published concerning diesel engine modelling and simulation, only Kyrtatos et al. [42] is focused on the investigation of a marine diesel engine steady state operation at slow steaming conditions. In addition, studies concerning the engine transient response at slow steaming conditions as well as the investigation of the influence of electric driven blower(s) running and the turbocharger cut-out on the engine operation were not found. In that respect, the objective of this research is to investigate the containership propulsion engine operation under steady state and transient conditions as well as to study the influence of the turbocharger cut-out and the blower running including the activation/deactivation phases on the engine response. The extension of the compressor map in the low speed region and the compressor map interpolation between the available constant speed curves are also carried out by developing an appropriate model based on the compressor non-dimensional parameters.

\section{Engine model description}

In this work, the MVEM that was described in Theotokatos [32] is used for modelling the investigated containership propulsion engine. The model is implemented in MATLAB/Simulink environment following a modular approach, as it is depicted in Fig. 1. Each part of the engine is represented by a 
block, which exchanges variables with the adjacent blocks of the model through the appropriate connections. The engine scavenging air and exhaust gas receivers are modelled as flow receiver elements (control volumes), whereas flow elements are used for representing the turbocharger compressor and turbine as well as the engine cylinders. Fixed fluid elements of constant pressure and temperature are used for modelling the engine boundaries. Shaft elements are used for calculating the engine crankshaft and turbocharger shaft rotational speeds. The engine governor element, which is used to adjust the engine fuel rack position, is considered to be of the proportional-integral (PI) type and incorporates the appropriate fuel rack limiters, whereas the propeller element is used for calculating the propeller torque. The properties of the working medium either air or gas are considered to be functions of temperature and fuel-air equivalence ratio.

The flow elements use as input the pressure, temperature and the properties of the working medium contained in the adjacent elements (flow receiver(s) or fixed fluid), whereas their output includes the mass and energy flow rates entering and exiting the flow element as well as the absorbed (for the case of compressor) or produced torques. The mass and energy flows are provided as input in the adjacent flow receiver elements, whereas the torques are required as input in the shaft elements. The output of turbocharger shaft element, i.e. the turbocharger speed, is forwarded to the compressor and turbine elements. The output of the crankshaft element includes the engine and propeller rotational speeds; the former is supplied as input to the engine cylinders and engine governor elements, whereas the latter is advanced in the propeller element.

The flow receiver elements are modelled using the open thermodynamic system concept $[43,44]$. The working medium mass and temperature are calculated using the following differential equations, which are derived by applying the mass and energy conservation laws in each volume, respectively: 


$$
\begin{gathered}
\frac{d m}{d t}=\dot{m}_{\text {in }}-\dot{m}_{\text {out }} \\
\frac{d T}{d t}=\frac{\dot{Q}_{h t}+(\dot{m} h)_{\text {in }}-(\dot{m} h)_{\text {out }}-u \frac{d m}{d t}}{m c_{v}}
\end{gathered}
$$

where $\dot{m}_{i n},(\dot{m} h)_{i n}$ are the mass and energy flow rates entering the flow receiver and $\dot{m}_{\text {out }},(\dot{m} h)_{\text {out }}$ are the mass and energy flow rates exiting the flow receiver, respectively. Subsequently, the working medium pressure is calculated using the ideal gas law.

No heat transfer is taken into account for modelling the scavenging air receiver, whereas the transferred heat from the gas contained in the exhaust gas receiver to the ambient is calculated using the exhaust gas receiver overall heat transfer coefficient and heat transfer area. The overall heat transfer coefficient in the exhaust receiver is calculated using a Nusselt-Reynolds number correlation for gas flowing in pipes [45].

The engine cylinders bank is regarded as a flow element, where the incoming air mass flow rate is calculated considering the equivalent of two consecutive orifices, each one representing the cylinders scavenging ports and exhaust valve, respectively [46]. Thus, the engine cylinders air mass flow rate is calculated according to the following equation, which was derived based on the subsonic flow consideration [44] using the equivalent cylinders flow area, the air properties and the pressures upstream and downstream of the engine cylinders:

$$
\dot{m}_{a}=c_{d} A_{e q} \frac{p_{S C}}{\sqrt{R_{a} T_{S C}}} \sqrt{\frac{2 \gamma_{\alpha}}{\gamma_{\alpha}-1}\left(p r_{c y l}^{\frac{2}{\gamma_{\alpha}}}-p r_{c y l}^{\frac{\gamma_{\alpha}+1}{\gamma_{\alpha}}}\right)}
$$

where $p r_{c y l}$ is the ratio of cylinder upstream and downstream pressures.

The equivalent orifice geometric area can be estimated using the instantaneous area variations for an engine cycle of the intake ports and exhaust valves, as follows $[33,46]$ :

$$
A_{e q}=\frac{z_{c y l}}{\Delta \phi_{c y}} \int_{0}^{\Delta \phi_{c y}} \frac{A_{s p}(\phi) A_{e v}(\phi)}{\sqrt{A_{s p}^{2}(\phi)+A_{e v}^{2}(\phi)}} \mathrm{d} \phi
$$


The mass flow rate of the exhaust gas exiting the engine cylinders is found by adding the mass flow rates of the air entering the engine cylinders and the injected fuel. The latter is calculated using the number of the engine cylinders, the engine rotational speed and the injected fuel mass per cylinder and per cycle. The injected fuel mass per cylinder and per cycle is regarded as function of engine fuel rack position, which is adjusted by the engine governor. The latter is modelled using a proportional-integral (PI) controller law with additionally incorporated torque and scavenging pressure limiters, as proposed and used by engine manufacturers for protecting the engine integrity during fast transients [23].

The energy flow rate exiting the engine cylinders element is calculated by taking into consideration the energy conservation equation and the fact that a portion of the fuel energy remains in the exhaust gas; thus:

$$
(\dot{m} h)_{c y l_{-} d}=\dot{m}_{a} h_{a_{-} c y l_{-} u}+\zeta \eta_{c o m b} \dot{m}_{f} H_{L}
$$

where $\zeta$ is fuel chemical energy proportion in the exhaust gas exiting engine cylinders.

The proportion of the fuel chemical energy contained in the exhaust gas is considered to be a function of the engine brake mean effective pressure [46], which is calculated using available engine performance data measured during the engine trials or provided by the engine manufacturer [47]. The indicated mean effective pressure is calculated using the rack position, the maximum indicated mean effective pressure of the engine and the combustion efficiency, which, in turn, is regarded as function of engine air to fuel ratio [43]. The friction mean effective pressure is considered to be function of the indicated mean effective pressure and the engine crankshaft speed [34]. The engine brake mean effective pressure is calculated by subtracting the friction mean effective pressure from the indicated mean effective pressure, whereas the engine torque is calculated using the brake mean effective pressure and engine cylinders displacement volume. 
The compressor is usually modelled using its steady state performance map [32,34], which is provided as input in a digitized form containing lines of the corrected compressor speed, pressure ratio, corrected flow rate and efficiency. Given the turbocharger shaft speed and the compressor pressure ratio, the corrected flow rate and efficiency are calculated using interpolation [32]. However, since the objective of this work is to investigate the engine operation at low loads that results in very low compressor shaft rotational speeds, a modified approach is followed justified by the fact that the compressor curves are not available in the region of very low speeds. According to that, the non-dimensional parameters functions are derived and used for each compressor map region as explained in the next section. However, the input/output parameters are kept the same as in the previous model versions [32,34]; the turbocharger speed and compressor pressure ratio are provided as input, whereas the mass flow rate and efficiency are derived as output.

The turbocharger shaft speed is taken from the turbocharger shaft element, whereas the compressor pressure ratio is calculated by the following equation using the pressure of the fixed fluid connected upstream the compressor, the pressure of the scavenging air receiver connected downstream the compressor, the air filter pressure drop, the air cooler pressure drop and the pressure increase in the auxiliary blower:

$$
p r_{C}=\frac{p_{S C}-\Delta p_{A C}+\Delta p_{B L}}{p_{a m b}-\Delta p_{A F}}
$$

where the air filter and air cooler pressure drops are considered to be proportional to the compressor air mass flow rate squared.

The temperature of the air exiting compressor is calculated according to the following equation, which was derived by manipulating the compressor isentropic efficiency definition equation [43]: 


$$
T_{C_{-} d}=T_{C_{-} u}\left(1+\left(p r_{C}^{\left(\gamma_{a}-1\right) / \gamma_{\alpha}}-1\right) / \eta_{C}\right)
$$

The compressor absorbed torque is calculated by the following equation:

$$
Q_{C}=30 \dot{m}_{C}\left(h_{C_{-} d}-h_{C_{-} u}\right) /\left(\pi N_{T C}\right)
$$

where the enthalpies of the air exiting the compressor and the air entering the compressor are calculated using the respective temperatures.

The temperature of the air exiting the air cooler is calculated based on the air cooler effectiveness definition equation [43] using the air cooler effectiveness and the temperature of the cooling water entering the air cooler. The air cooler effectiveness is assumed to be a polynomial function of the air mass flow rate.

When the electric driven blower operates, it discharges the air exiting the air cooler to the engine scavenging receiver. The blower pressure increase is regarded as function of its air volumetric flow rate according to the following equation:

$$
\Delta p_{B L}=k_{B L, 0}+k_{B L, 1} \dot{V}_{B L}+k_{B L, 2} \dot{V}_{B L}^{2}
$$

The temperature of the air exiting the blower is calculated using the temperature of the air entering the blower, the blower efficiency and pressure ratio (Eq. (7) replacing index C with BL).

The turbine is modelled using its swallowing capacity and efficiency maps, which must be provided in digitized form. Given the turbine pressure ratio, the turbine mass flow rate and efficiency are calculated using interpolation.

The turbine pressure ratio is calculated using the pressure of the exhaust gas receiver, the ambient pressure downstream the engine exhaust pipe and the exhaust pipe pressure loss, as follows:

$$
p r_{T}=\frac{p_{E R}}{p_{a m b}+\Delta p_{e p}}
$$

The pressure loss of the exhaust piping system is regarded as proportional to the exhaust gas mass flow 
rate squared. The temperature of the gas exiting turbine is calculated based on the turbine isentropic efficiency definition equation [43] using the temperature of gas entering turbine, and the turbine pressure ratio and efficiency.

The turbine torque provided to the turbocharger shaft is derived by using the following equation:

$$
Q_{T}=30 \dot{m}_{T}\left(h_{E R}-h_{T, d}\right) /\left(\pi N_{T C}\right)
$$

where the enthalpies of the gas exiting the turbine is calculated using the respective temperature, whereas the enthalpy of the gas entering the turbine is taken from the upstream exhaust gas receiver element.

The engine crankshaft and turbocharger shaft rotational speed calculation is carried out in the shafting system and turbocharger shaft elements, respectively. The former uses the engine and propeller torques fed from the engine cylinders and propeller elements, respectively; the latter uses the compressor and turbine torques supplied form the respective elements. The propeller torque is calculated by applying the propeller law equation passing through the engine maximum continuous rating (MCR) point.

The engine crankshaft and turbocharger shaft rotational speeds are calculated by integrating the following equations derived using the angular momentum conservation in the propulsion plant shafting system and the turbocharger shaft, respectively:

$$
\begin{aligned}
\frac{d N_{E}}{d t} & =\frac{30\left(\eta_{S h} Q_{E}-Q_{P}\right)}{\pi\left(I_{E}+I_{S h}+I_{P}+I_{e w}\right)} \\
\frac{d N_{T C}}{d t} & =\frac{30\left(Q_{T}-Q_{C}\right)}{\pi I_{T C}}
\end{aligned}
$$

According to the mean value engine modelling approach and considering Eq. (3) to (5), the cylinders discharge coefficient $\left(c_{d}\right)$ and the fuel chemical energy proportion in the exhaust gas exiting cylinders $(\zeta)$ are the critical input parameters that affect the model predictive capability. Especially, for the case of electronically controlled versions of marine Diesel engines, which use variable timing for fuel injection and exhaust valve opening/closing, attention must be paid when estimating these parameters in a 
pre-processing model phase. Since both variable injection timing and exhaust valve opening/closing timing are controlled by considering the engine load, the used function of $\zeta$ versus brake mean effective pressure is regarded as sufficient. Considering Eq. (5), $\zeta$ can be calculated using the air and fuel mass flow rates, the scavenging receiver air temperature, the exhaust receiver gas temperature, the fuel lower heating value as well as the specific heat at constant pressure of air and gas. Considering Eq. (3), the discharge coefficient can be derived by using the air mass flow rate, the cylinder pressure ratio, the pressure and temperature of the air contained in the scavenging receiver and the air properties. The required parameters can be obtained by using the engine performance data either measured during the engine trials or provided by the engine manufacturer [47]. However, in case where the fuel injection and/or exhaust valve opening/closing timings depend on both the engine load and speed, a two dimensional mapping for the model input parameters must be used, which complicates the mean value model set up. Therefore, a zero-dimensional model usage is recommended in such cases.

\section{Extension of compressor performance map}

\subsection{Extrapolation/interpolation of pressure ratio curve}

The steady-state compressor performance maps are always given in terms of corrected quantities, due to the fact that the compressor performance parameters are measured at various ambient conditions. The compressor performance maps usually provide curves of pressure ratio versus corrected mass or volumetric flow rate for constant values of corrected compressor speed and the iso-contours of the compressor efficiency. The compressor corrected speed and volumetric flow rate are given by the following equations [48]: 


$$
\begin{gathered}
N_{c o r}=\frac{N}{\sqrt{T / T_{r e f}}} \\
\dot{V}_{c o r}=\frac{\dot{V}_{C}}{\sqrt{T / T_{r e f}}}
\end{gathered}
$$

where $p_{\text {ref }}$ and $T_{r e f}$ denote the reference pressure and temperature, respectively and accompany the compressor map.

The compressor map provided by the compressor manufacturer typically covers the rotational speed area from $40 \%$ to $100 \%$ of the maximum turbocharger speed. Thus, the compressor map extension to the lower speed region is required in order to accurately evaluate the engine performance at low loads. In this study, the compressor non-dimensional flow and isentropic head coefficients ( $\varphi$ and $\Psi$ respectively), which were derived by the following equations, were used for the compressor constant speed curves extrapolation at low speeds as well as for interpolation between two given constant speed curves.

$$
\begin{gathered}
\varphi=\frac{\dot{V}_{C}}{A_{C} U_{C}} \\
\Psi=\frac{p r_{C}^{\frac{\gamma-1}{\gamma}}-1}{(\gamma-1) M_{i n l}^{2}}
\end{gathered}
$$

The compressor impeller tip Mach number used in Eq. (17) is defined by the following equation:

$$
M_{i n l}=\frac{U_{C}}{\sqrt{\gamma R T_{a m b}}}=\frac{\pi N_{T C} D_{T}}{60 \sqrt{\gamma R T_{a m b}}}
$$

The relationship between non-dimensional flow and isentropic head coefficients can be represented using the following equation according to [36], in which the impeller tip Mach number was also included to capture the speed dependency and therefore further enhance the model accuracy.

$$
\varphi=\frac{k_{1}+k_{2} M_{i n l}+k_{3} \Psi+k_{4} M_{i n l} \Psi}{k_{5}+k_{6} M_{i n l}-\Psi}
$$

The compressor map curves of pressure ratio versus corrected volumetric flow rate at constant speed are shown in Fig. 2. The compressor map was divided into 8 zones depending on the available constant 
speed curves. For the zone 2 to 8, Eq. (19) was used to interrelate the compressor non-dimensional parameters and a set of values for the parameters $k_{1}$ to $k_{6}$ were derived based on the two curves delimiting a zone, as proposed in Guillaume et al. [37]. For calculating the non-dimensional flow coefficient at zone 1 , the calculated values of $k_{1}$ to $k_{6}$ for zone 2 were used, since curves at the compressor lowest speed region were not available. Thus, 7 sets of parameters $\left(k_{1}\right.$ to $\left.k_{6}\right)$ were calculated using the curve fitting tool in MATLAB providing as input the triplets of $\varphi, \Psi$ and $M_{\text {inl }}$ derived from the available compressor map curves. As an example, the surface interrelating the non-dimensional compressor parameters, which was calculated for zone 3, is shown in Fig. 3. The obtained R-square value for that zone is 0.9985 ; similar values of R-square were calculated for the other zones. This indicates that the applied surface fitting successfully capture the $\varphi, \Psi$ and $M_{i n l}$ interrelation.

\subsection{Validation of the method accuracy}

Since no experimental data were available for the validation of the non-dimensional parameters method results, a corrected similarity laws approach was used. The similarity laws are a useful tool, as they allow prediction of the head characteristic of a turbomachine at a given rotational speed using a known characteristic curve measured at a different speed or impeller diameter [49]. The approach developed in this study to validate the non-dimensional parameters method for extrapolating the compressor performance map in low speed region used the basic principles of the similarity laws as discussed in Munson et al. [49]. Assuming incompressible fluid, the following equation was derived for the calculation of pressure ratio in the similar operating point at speed $N_{2}$ based on the pressure ratio $p r_{1}$ of the known compressor operating point at speed $N_{1}$ by manipulating the similarity laws equation relating head and speed: 


$$
p r_{2}=\left(p r_{1}-1\right)\left(\frac{N_{1}}{N_{2}}\right)^{2}+1
$$

However, air, which is the working fluid in the compressor, cannot be considered as incompressible especially at high compressor rotational speed. Therefore, when similarity laws are used to calculate the pressure ratio curve based on the respective available curves values at higher speed, a notable deviation between the calculated and actual compressor curves can be found, as shown in Fig. 4 .

The deviations seen from Fig. 4 are owing to the ignorance of compressibility effects when applying the similarity laws. In comparison to the available compressor map curves, it can be inferred that the calculated pressure ratio/corrected volumetric flow rate curve using similarity laws based on the higher speed curve should be lowered to some extent in reality. For lower values of compressor speed, the compressibility of the fluid has less influence and therefore, the observed deviations between the curves calculated using similarity laws and the available compressor map curves are smaller. Especially when speed is very small (below $20 \%$ of its maximum value), the deviation will be insignificant and can be neglected. The averaged deviation of pressure ratio and corrected volumetric flow rate can be represented as the following function of corrected compressor rotational speed:

$$
D_{X}=k_{X, 1} \cdot \exp \left(k_{X, 2} \cdot N_{T C}\right) \quad \text { with } X=\dot{V} \text { or } p r
$$

Based on the calculated pressure ratio and volumetric flow rate deviation values, the constants $k_{X, 1}$ and $k_{X, 2}$ of Eq. (21) were calculated using the MATLAB curve fitting tool. Then, those corrections were applied for estimating the pressure ratio/volumetric flow rate curves at lower speeds. The extrapolation results based on the corrected similarity laws compared with the results derived from the non-dimensional parameters method are shown in Fig. 5. From that figure, it can be inferred that the curves calculated using the corrected similarity laws approach almost coincide with the curves derived by using the non-dimensional parameters method. The non-dimensional parameters method results for 
interpolating between the available compressor map curves and their comparison with the respective curves derived using a linear interpolation method are also presented in Fig. 5. It can be inferred that there is a very good agreement between the results derived using both methods. As a result, the non-dimensional parameters method provides results of adequate accuracy in very low speed region and in the region between the available speeds. Therefore, it was decided to implement it in the engine simulation model as a new compressor model. According to this model, the following steps are applied for calculating the corrected compressor volumetric flow rate for given the values of the compressor speed and pressure ratio. First, the corrected speed, the non-dimensional isentropic head coefficient and the impeller tip Mach number are calculated. Then, the respective zone is identified based on the corrected speed. And subsequently Eq. (19) and (16) are used for calculating the non-dimensional flow coefficient and the compressor volumetric flow rate, respectively.

\subsection{Calculation of compressor isentropic efficiency}

To calculate the isentropic efficiency of the compressor, the non-dimensional torque coefficient $\Gamma_{C}$ was used, which is defined by the following equation [50]:

$$
\Gamma_{C}=\frac{Q_{C}}{\rho A_{C} r_{C} U_{C}^{2}}
$$

The relationship between the compressor non-dimensional torque and flow coefficients is almost linear for each speed curve, as can be also derived from Fig. 6. Therefore, the following equation was used for calculating the non-dimensional torque coefficient:

$$
\Gamma_{c}=k_{1} \varphi+k_{2}
$$

The values of $k_{1}$ and $k_{2}$ constants (slope and y-intercept) of Eq. (23) were calculated using the data points of each speed curve; the obtained values of R-square were found to be between 0.8896 and 0.9971 . 
The lowest value was derived for the highest speed curve, whereas values of R-square above 0.96 were calculated for the lowest six speed curves. For calculating $\Gamma_{C}$ at compressor operating points within the zones 2 to 8 , the coefficients $k_{1}$ and $k_{2}$ of Eq. (23) were estimated by applying linear interpolation using their respective values for the higher and lower speed curves, according to the following equation:

$$
k_{j, \text { zone } i}=k_{j, \text { lower }}+\frac{\left(k_{j, \text { higher }}-k_{j, \text { lower }}\right)}{\left(N_{\text {higher }}-N_{\text {lower }}\right)}\left(N_{T C}-N_{\text {lower }}\right) \quad \text { for } i=2-8 ; j=1,2
$$

For calculating the non-dimensional torque coefficient within zone 1 , the values of the constants $k_{1}$ and $k_{2}$ in Eq. (23) were considered to be the ones derived for the lowest available corrected compressor speed curve. With given the compressor flow rate, the non-dimensional flow coefficient can be calculated according to Eq. (16), and subsequently, the non-dimensional torque coefficient, $\Gamma_{c}$, can be derived based on Eq. (23). Then, Eq. (22) was applied to calculate the compressor torque, whereas the compressor isentropic efficiency was calculated using the following equation, which was derived from the compressor efficiency definition [43]:

$$
\eta_{C, \text { non-cor }}=\frac{30 \gamma R \dot{V}_{C} \rho T_{a m b}}{\pi N(\gamma-1) Q_{C}}\left(p r_{C}^{\frac{\gamma-1}{\gamma}}-1\right)
$$

\subsection{Compressor isentropic efficiency correction}

The efficiency calculated using Eq. (25) may differ from the actual compressor isentropic efficiency, since compressibility effects are not considered and the compressor components losses are dependent on the compressor speed, pressure ratio and flow rate. After analyzing the available compressor map, it was derived that the maximum compressor isentropic efficiency has a quadratic dependency on the corrected turbocharger shaft speed, as shown in Fig. 7. In order for the corresponding maximum efficiency to be consistent with its respective actual value derived using Fig. 7, the compressor isentropic efficiency calculated using Eq. (25) needs to be corrected. In that respect, the compressor isentropic efficiency was 
corrected using the following equation:

$$
\eta_{C, \mathrm{cor}}=\eta_{C, \text { non-cor }} \frac{\eta_{C \max }\left(N_{T C}\right)}{\eta_{C, \text { non-cor } \max }\left(N_{T C}\right)}
$$

where $\eta_{C \max }\left(N_{T C}\right)$ denotes the maximum compressor isentropic efficiency for the examined rotational speed $N_{T C}$ and $\eta_{C, \text { non-cor,max }}\left(N_{T C}\right)$ denotes the maximum efficiency calculated by using Eq. (25) for the compressor characteristic at that speed.

The available compressor isentropic efficiency curves, the calculated curves in the lowest speed region (zone 1) as well as the calculated compressor curves within the available speed range are presented in Fig. 8. The following conclusions can be derived by analysing the results shown in that figure. When extrapolating the compressor maps at the lower speed region, the deviation of the non-corrected efficiency values increases as the compressor speed reduces. Thus, the applied correction is considered to be indispensable. Smaller deviation is observed between the non-corrected efficiency and the respective values calculated using linear interpolation based on the available efficiency curves. However, by applying the proposed correction, excellent accuracy is obtained and additionally the predictions become consistent with the expected maximum efficiency trend. From the previous analysis, it is inferred that the proposed method for calculating compressor efficiency can be used for extrapolating and interpolating the available compressor efficiency curves and therefore, it was decided to incorporate it to the new compressor model, which was implemented to the considered engine model.

In summary, the extension of the compressor map and its implementation to the engine model consists of the pre-processing phase and the model execution phase. The pre-processing phase includes the elaboration of the compressor map and the model set up as follows:

- Divide the compressor map into zones depending on the available constant speed curves

- Digitize the provided compressor performance map

- Calculate the non-dimensional parameters $\varphi, \mathrm{M}_{\mathrm{inl}}, \Psi$ and $\Gamma_{\mathrm{c}}$ for the digitised compressor operating points 
- Derive the values of the parameters $\mathrm{k}_{1}$ to $\mathrm{k}_{6}$ for each zone based on Eq. (19) using curve fitting techniques

- Derive the values of the parameters $k_{1}$ and $k_{2}$ for each speed curve based on Eq. (23) using curve fitting techniques

- Derive the equations interrelating the actual maximum compressor efficiency with speed and the non-corrected maximum compressor efficiency with speed, which are used in Eq. (26) using curve fitting techniques

- $\quad$ Provide all the above parameters as input to the compressor model

The following calculation steps are applied through model running considering as additional input the compressor pressure ratio and shaft speed:

- Calculate the corrected speed and identify the respective compressor map zone

- Calculate the non-dimensional parameters $M_{\text {inl }}$ and $\Psi$ from Eq. (18) and (17), respectively

- Calculate the non-dimensional flow coefficient $\varphi$ from Eq. (19) using the values of $\mathrm{k}_{1}$ to $\mathrm{k}_{6}$ for the respective zone

- Derive the compressor volumetric flow rate using Eq. (16)

- Calculate the non-dimensional torque coefficient, $\Gamma_{c}$, from Eq. (23) by using values of $\mathrm{k}_{1}$ and $\mathrm{k}_{2}$ for the respective zone

- Calculate the compressor torque according to Eq. (22)

- Calculate the non-corrected compressor isentropic efficiency based on Eq. (25)

- $\quad$ Derive the corrected compressor isentropic efficiency according to Eq. (26)

\section{Test case}

The two-stroke marine diesel engine MAN B\&W 12K98ME-C was simulated using the described

MVEM having incorporated the modified compressor model for extrapolating the compressor map in the low speed region and interpolating between the available constant speed curves. That engine is typically used as the propulsion engine of large containerships. The engine crankshaft is directly connected to the ship fixed pitch propeller via the ship shafting system. The engine is turbocharged operating on the constant pressure turbocharging system concept using four turbocharger units. One air cooler unit is installed downstream each compressor in order to cool the hot compressed air. In addition, four electric driven blowers are used for providing adequate air flow when the engine operates at load below $35 \%$. Each blower receives the air exiting the respective engine air cooler unit and discharges that to the engine 
scavenging air receiver. The blowers are activated when the engine air scavenging receiver pressure becomes lower than 1.55 bar, whereas they are switched off for pressure values greater than 1.7 bar. The main engine characteristics as well as the required input data were extracted from the engine manufacturer project guide [51]. The engine steady state performance data were obtained from the engine shop trial measurements as well as by using the engine manufacturer web-based Computerized Engine Application System-Engine Room Dimensioning (CEAS-ERD) [47]. The main engine parameters are given in Table 1.

The mean value engine model was set up providing the required input data, which included the engine geometric data, the turbocharger compressor and turbine performance maps, the engine ambient conditions, the constants of engine model equations and the propeller loading. Initial conditions are also required for the variables that are calculated by integrating differential equations, i.e. the engine/propeller shaft and turbocharger shaft rotational speeds as well as the pressure and temperature of air and gas contained in the engine receivers, respectively. The engine four turbocharger units as well as the installed air coolers and blowers were considered to have identical performance.

For validating the engine model, simulation runs under steady state operating conditions at $25 \%, 50 \%$, $75 \%, 85 \%$ and $100 \%$ of the engine MCR load were performed. The engine blowers are activated at loads lower that $35 \%$ of the engine MCR point, since the scavenging air receiver pressure is lower than 1.55 bar. The percentage error between the predicted engine performance parameters and the respective shop trial data are given in Table 2. Predictions of sufficient accuracy are obtained not only for high engine load region but also for the engine operation at $25 \%$ load. Therefore, the engine model as well as the used compressor extrapolation/interpolation method and the blower submodel are considered to provide satisfactory prediction accuracy and they can be used with fidelity for studying the engine operation at 
slow steaming simulations.

Having validated the engine model, the engine steady state operation was examined covering the operating region from $15 \%$ to $100 \%$ load. A set of the predicted engine performance parameters including the receivers pressures and temperatures, the temperature of the exhaust gas exiting the engine, the turbocharger speed, the brake specific fuel consumptions corrected at ISO conditions, the brake power and the total air to fuel ratio is presented in Fig. 9. The respective parameter values obtained from the engine shop trials for the engine loads $25 \%, 50 \%, 75 \%, 85 \%$ and $100 \%$ and from the engine manufacturer web application [47] for the load range from $15 \%$ to $100 \%$ are also shown in Fig. 9. It must be noted that according to [47], the provided data are only for guidance and are associated with tolerances $\pm 5 \%$ for brake specific fuel consumption and $\pm 15^{\circ} \mathrm{C}$ for the temperature of the exhaust gas exiting turbine. Greater tolerances may be effective for engine loads below 35\%. Good agreement is obtained between the simulation results and the data provided by the engine manufacturer for the majority of the engine parameters. Some deviation is observed in the prediction of temperature of the exhaust gas exiting turbine for loads lower than $35 \%$, although its variation with load is qualitatively predicted. That can be attributed to the turbine efficiency, which was not given for the data derived from [47], since the engine manufacturer does not provide the details of the turbocharger. However, it can be inferred considering Fig. 9 that the model provides adequate accuracy for modelling the engine performance in the whole engine operating envelope.

The minimum value of the temperature of the exhaust gas exiting turbines and brake specific fuel consumption are observed at $85 \%$ load. This means that the engine and its turbochargers were optimized for that load, which was reasonable for the time that the containership was designed (almost 10 years ago), when slow steaming operation was not included as an option at the ship design phase. As the engine 
load reduces down to $35 \%$, the temperature of the exhaust gas exiting turbines increases. This is owing to the lower air to fuel ratio values as a result of the lower air flow entering the engine cylinders that caused by the reduction of the turbocharger speed at lower engine loads. Due to the activation of the engine blowers, discontinuities in the engine performance parameters variations are observed between $30 \%$ and $35 \%$ load. The blower activation results in a higher air flow entering the engine cylinders and thus increases the air to fuel ratio. Therefore, the temperature of the exhaust gas contained in the engine receiver and the temperature of the gas exiting turbine reduce approximately $45 \mathrm{~K}$ compared to their respective values at $35 \%$ load (where the blowers are not activated). In addition at engine load $30 \%$ and lower, the scavenging air receiver temperature increases around $5 \mathrm{~K}$ compared to the respective value of approximately $300 \mathrm{~K}$ at $35 \%$ load. This is attributed to the blower compression process, which results in $1.67 \%$ air temperature rise, according to Eq. (7). At even lower engine loads (20\% and $25 \%$ ), the exhaust gas temperature slightly increases due to the fact the engine air flow rate becomes smaller since the compressor operates at lower speed. At $15 \%$ engine load, there is a decrease in the exhaust gas temperature, which is attributed to the fact that the reduction of the fuel amount injected to engine cylinders, which is much greater than the respective air flow rate reduction and as a result, the air to fuel ratio increases. The same behaviour in the exhaust gas and air temperatures can be found using the engine manufacturer CEAS-ERD application [47], as shown in Fig. 9.

As an alternative, the cut-out of one turbocharger unit can be used instead of the blower activation at slow steaming operation. Comparison of the engine performance parameters in these two cases for engine loads below $50 \%$ are presented in Fig. 10. The cut-out of one turbocharger unit resulted in a considerable increase of the scavenging receiver pressure and turbocharger speed from $50 \%$ engine load down to $25 \%$ load and a slight increase of these two parameters for the load range from $15 \%$ to $25 \%$. In 
addition, since the blowers were not activated, the scavenging receiver temperature remained almost constant, close to $300 \mathrm{~K}$ for the load range from $15 \%$ to $50 \%$. Therefore, greater amount of fresh air can be provided to the engine cylinders as it is inferred by the values of the engine air to fuel ratio, which are greater in the region from $35 \%$ to $50 \%$ load (where the blowers were deactivated) and almost the same for the region within $25 \%$ to $30 \%$ load (where the blowers were activated). Thus, the turbocharger cut-out resulted in a reduction of the temperature of the exhaust gas and the consequential lowering of the engine thermal loading for engine load region from $35 \%$ and above. In addition, since the exhaust gas receiver pressure was greater for the load region above $25 \%$, the turbine pressure ratio was also greater, resulting in increased turbine efficiency. Therefore lower temperature of the exhaust gas exiting turbines was obtained, which means greater work extraction in the turbines of the operating turbocharger units. Only for engine loads below $25 \%$, the turbocharger speed significantly reduced reaching $2670 \mathrm{rpm}$ at $15 \%$ load, and as a result the air to fuel ratio was lower than the one obtained for the case of blower activation, Thus, the exhaust gas temperature significantly increased below $20 \%$ load, which means that the three turbocharger units operation was no longer sufficient to maintain the required engine air flow. Therefore, either cut-out of another turbocharger unit or activation of blowers must be applied below $20 \%$ to $25 \%$ load.

The next step was to examine the model ability to capture the engine transient response at slow steaming conditions. In that respect, simulation runs applying engine load changes from $45 \%$ to $25 \%$ at the $50^{\text {th }} \mathrm{s}$ and from $25 \%$ to $40 \%$ at the $250^{\text {th }} \mathrm{s}$ were performed. These correspond to engine speed changes from $79.7 \mathrm{rpm}$ to $65.5 \mathrm{rpm}$ for the unloading period and then from $65.5 \mathrm{rpm}$ to $76.6 \mathrm{rpm}$ for the loading period. A set of the derived simulation results including the scavenging air receiver pressure, the air to fuel ratio, the exhaust gas receiver temperature and the turbocharger speed, is presented in Fig. 11 for the 
following two cases: a) considering blowers activation/deactivation and, b) considering blowers do not operate. The respective trajectories of the compressor operating points superimposed on the compressor map are shown in Fig. 12. Considering Fig. 12, the following compressor operating points were found for the investigated case (a): point 1 corresponds to the simulation starting point ( $45 \%$ engine load), point 2 corresponds to the blowers activation, point 3 is the compressor operating point obtained for $25 \%$ engine load, point 4 corresponds to blowers deactivation and point 5 is the final compressor operating point at $40 \%$ engine load. The following points were obtained for the case (b): point 1 corresponds to the simulation starting point at $45 \%$ engine load, point 2 ' corresponds to $25 \%$ engine load and point 5 is the final compressor operating point at $40 \%$ engine load.

The compressor operation after the blower activation/deactivation is characterized by a sharp increase/decrease of the air flow followed by a restoration period that lasts approximately $6 \mathrm{~s}$. For the case (a), where the blowers are considered to normally operate, the following results were obtained. The blowers were activated at $83^{\text {th }} \mathrm{s}$, when the scavenging air receiver pressure became lower than 1.55 bar. This resulted in a considerable increase of the engine air flow and therefore, the unloading engine phase continued at greater scavenging air receiver pressure, turbocharger speed and air to fuel ratio values as well as lower exhaust receiver temperature, compared to the respective values obtained for the case (b) where the blowers do not operate. The predicted compressor operating point at $25 \%$ engine load for the case (a) (point 3) had much greater flow rate, pressure ratio and turbocharger speed than the respective parameters of point 2', which was predicted for the case (b). In addition, for the engine operation at $25 \%$ load, the exhaust gas receiver temperature was much lower $(602 \mathrm{~K}$ for the case (a) compared to $733 \mathrm{~K}$ for the case (b)), whereas the air to fuel ratio, the scavenging air receiver pressure and turbocharger speed were greater compared to their values obtained for the case (b). 
During the engine loading period, the turbocharger speed as well as the scavenging air receiver pressure increased, and the blowers were deactivated at $304^{\text {th }} \mathrm{s}$, when the scavenging receiver pressure became greater than 1.7 bar. This resulted in sharp decrease in the engine air flow, scavenging air receiver pressure and air to fuel ratio and an increase in the exhaust gas temperature. During the initial part of the engine loading period (from $250^{\text {th }} \mathrm{s}$ to $280^{\text {th }} \mathrm{s}$ ), a continuous increase in the exhaust gas receiver temperature is observed due to the turbocharging system lag. The maximum predicted exhaust gas receiver temperature reached $650 \mathrm{~K}$ at $285^{\text {th }} \mathrm{s}$, and subsequently, it remained almost constant as the turbocharger speed had increased and thus adequate air amount entered the engine cylinders; the air to fuel ratio value started gradually increasing after $285^{\text {th }} \mathrm{s}$. Therefore, the blowers were not needed after $300^{\text {th }} \mathrm{s}$ and they were deactivated at $304^{\text {th }} \mathrm{s}$. This caused a sharp increase of approximately $5 \mathrm{~K}$ to the exhaust gas receiver temperature, which reached $655 \mathrm{~K}$. At that point, however, the turbocharger speed was enough for providing the required air flow and thus, the exhaust gas receiver temperature started reducing and reaching its final steady state value of $630 \mathrm{~K}$. Thus, during the engine loading period, the exhaust gas receiver temperature obtained a maximum value $25 \mathrm{~K}$ greater than its final steady state value. On the contrary, the engine/turbocharger operation for the case (b) demonstrated slower response since their performance parameters reached steady state conditions approximately $45 \mathrm{~s}$ later than the ones in the case (a). In addition, the obtained maximum exhaust gas receiver temperature was much higher (reaching $800 \mathrm{~K}$ ) during the engine loading period. Therefore, it can be inferred that the engine thermal loading will be prohibitively increased in the case where the blowers do not operate and the blowers activation is required in order for the engine to safely operate at the low loads region.

For further investigating the engine model prediction capability at very low loads, a transient engine operation from $45 \%$ load to $15 \%$ load was simulated considering that a) the blowers operate, b) the 
blowers do not operate and c) cut-out of one turbocharger unit and deactivated blowers. The simulation results including the compressor operating points trajectories and a set of engine performance parameters are presented in Fig. 13 and 14, respectively. Considering Fig. 13, point 1 corresponds to the simulation starting point (45\% load) for cases (a) and (b), point 1' is the simulation starting point for case (c), point 2 is the point where the blowers were activated (for case a), whereas points 3,2' and 2" are the final compressor operating points (at 15\% engine load) for the cases (a), (b) and (c), respectively. The final predicted values of the turbocharger speed were found to be $2475 \mathrm{rpm}, 1581 \mathrm{rpm}$ and $2658 \mathrm{rpm}$ for the cases (a), (b) and (c), respectively; all are much lower than $5700 \mathrm{rpm}$ that corresponds to the lowest available compressor speed curve. In addition, as far as the cylinder pressure difference is calculated to be positive (scavenging air receiver pressure is greater than the exhaust receiver pressure), the engine model provides predictions for the engine performance parameters. The above demonstrate the ability of the engine model in conjunction to the developed compressor model to capture the engine and compressor operation at very low loads.

For the case (a), the blowers were activated at $75^{\text {th }} \mathrm{s}$ (point 2) and that resulted in a considerable increase of the air flow entering the engine cylinders, a $6 \mathrm{~K}$ increase of the scavenging air receiver temperature due to the air compression in the blowers, and a slight increase of the engine cylinders pressure difference. The additional air flow resulted in lower temperature level in the exhaust gas receiver, greater cylinder pressure difference and turbocharger shaft speed, compared to the respective values for the case where the blowers do not operate. As it can be derived from Fig. 14, the final exhaust gas receiver temperature at $15 \%$ load was calculated at $577 \mathrm{~K}$ and $803 \mathrm{~K}$ for the cases (a) and (b) respectively, which indicates that the engine thermal loading will be significantly increased when the blowers do not operate. In conclusion, when the engine operates at very low loads, the electric driven 
blowers activation can maintain the required engine air flow, increase the turbocharger shaft speed and the cylinders pressure difference and keep the engine thermal loading in an acceptable level.

For the case (c) with one turbocharger unit cut-out, the operating turbochargers speed was considerably greater at the simulation starting point comparing to the respective value for cases (a) and (b) (7869 rpm instead of $6546 \mathrm{rpm}$ ) and that resulted in greater turbocharger speed throughout the simulation run reaching a final value of $2658 \mathrm{rpm}$ (point 2"). The final value of the temperature of the exhaust receiver was calculated at $674 \mathrm{~K}$ and it was found to be greater than the one of case (a). In addition, the obtained cylinder pressure difference was lower than the one of case (a). The above indicate that the one turbocharger unit cut-out can lead to an acceptable engine behaviour and thermal loading at low loads down to $25 \%$, but for engine operating at ultra-slow steaming conditions ( $10 \%$ to $25 \%$ engine load), another turbocharger unit cut-out or activation of the engine blowers are required.

\section{Conclusions}

The investigation of the operation of a large containership main engine was performed at steady state and transient conditions with emphasis at very low engine loads based on a modular mean value engine model implemented in the MATLAB/Simulink environment. That was combined with a new compressor model, which was developed based on the non-dimensional compressor parameters approach, capable of extrapolating the compressor map to the low speed region and interpolating between the available constant speed curves. In addition, the electric driven blower submodel was jointly used for capturing the influence of the blower operation including the phases of activation/deactivation on the engine performance. The main conclusions derived from this work are summarized as follows.

The used engine simulation tool is capable of predicting with sufficient accuracy the engine steady 
state performance and transient response even in the region of very low engine loading. The engine model can provide results as far as the cylinder pressure difference is calculated to be positive, since it is prerequisite in order for a two-stroke marine diesel engine to keep running. The compressor extension method was sufficiently used to extrapolate the compressor map for speed values down to $1000 \mathrm{rpm}$, which corresponds to compressor operation at less than $10 \%$ of its maximum speed and engine operation at loads below $15 \%$ of its MCR point.

When the engine operates at the moderate to low loads region (lower than 50\%), the temperature of the exhaust gas exiting turbines increases as the engine load reduces since the engine air to fuel ratio becomes lower, reaching values around $600 \mathrm{~K}$ at $35 \%$ load. Therefore, the blower activation is vital below that engine loading point for ensuring the safe engine operation. The blower switching on results in a considerable increase of the engine air flow, thus increasing the engine air to fuel ratio and reducing the exhaust gas temperature, which has as a consequence to maintain the engine thermal loading in an acceptable level. As an alternative, the cut-out of one turbocharger unit can render the operation of the engine with the blowers deactivated down to $25 \%$ load. However, one additional turbocharger unit cut-out or alternatively the blower activation are required, so that the engine operates appropriately at the lowest load region ( $10 \%$ to $25 \%$ load).

The blower activation/deactivation results in a sharp increase/decrease in the air flow, scavenging pressure and air to fuel ratio that it is followed by a restoration period of a few seconds. During the engine unloading towards very low loads, the engine response becomes faster after the engine blowers activation and the engine reaches its steady state conditions sooner than the respective case where the blowers do not operate. During the engine loading starting from very low loads, the blowers operation attenuates the turbocharger lag effect on the engine performance. Therefore, the increase of turbocharger 
speed is more rapid and the resultant compressor air flow is greater, which results in moderate exhaust gas temperature overshoot. The blowers are deactivated at the point where the turbochargers can maintain the required engine air flow. Although that resulted in a sharp slight increase in the exhaust gas temperature and a respective decrease in the scavenging air receiver pressure, the turbocharger continues increasing its speed and the engine reaches its steady state point faster than the respective case without blower operation, since greater amount of energy is contained in the exhaust gas entering turbines. The engine operation at low loads without blower activation will result in significant increase of exhaust gas temperature as well as the resultant thermal loading, and therefore, it is regarded to be prohibitive. This can be overcome by using cut-out of one or more turbocharger units.

Since it is expected that the slow steaming will be continuously used by the ship operators, the developed engine model will be a useful tool for investigating the engine steady state performance and the propulsion system transient response, for examining measures to reduce the engine fuel consumption and efficiency, e.g. turbocharger isolation or variable geometry turbine turbochargers, and for designing and testing control schemes.

Acknowledgments The research work performed by Mr. Guan and Prof. Chen was supported by the Fundamental Research Funds for the Central Universities of China (No. 2013-JL-002), and by the Programme of Introducing Talents of Discipline to Universities (B08031). Further, the authors would like to express their sincere gratitude to Mitsubishi Heavy Industries for providing the compressor performance map and Doosan Engine Co., Ltd for providing the engine shop trial measurements. 


\section{References}

[1] Carolina GM, Julio R, Maria JS. Modelling and forecasting fossil fuels, CO2 and electricity prices and their volatilities. Applied Energy 2013; 101: 363-375.

[2] Chuanguo Z, Xiaoqing C. The impact of global oil price shocks in China's bulk commodity markets and fundamental industries. Energy Policy 2014; 66: 32-41.

[3] Yuejun Z, Ziyi W. Investigating the price discovery and risk transfer functions in the crude oil and gasoline futures markets: Some empirical evidence. Applied Energy 2013; 104: 220-228.

[4] Haakon L, Egil J, Inge S. Reductions in cost and greenhouse gas emissions with new bulk ship designs enabled by the Panama Canal expansion. Energy Policy 2013; 59: 341-349.

[5] Notteboom TE. The time factor in liner shipping services. Maritime Economics \& Logistics 2006; 8(1): 19-39.

[6] Notteboom TE, Vernimme B. The effect of high fuel costs on liner service configuration in container shipping. Journal of Transport Geography 2011; 17(5): 325-337.

[7] UNCTAD. Review of Maritime Transport 2013. UNCTAD/RMT/2013.

[8] IMO. Air pollution and energy efficiency-Estimated $\mathrm{CO} 2$ emissions reduction from introduction of mandatory technical and operational energy efficiency measures for ships. International Maritime Organisation. London. 31 October 2011. MEPC 63/INF.2.

[9] Molina S, Guardiola C, Martin J, Garcia SD. Development of a control-oriented model to optimize fuel consumption and NOx emissions in a DI Diesel engine. Applied Energy 2014; 119: 405-416.

[10] Jie L, Fuyuan Y, Hewu W, Minggao O, Shougang H. Effects of pilot fuel quantity on the emissions characteristics of a CNG/diesel dual fuel engine with optimized pilot injection timing. Applied Energy 2013; 110: 201-206.

[11] Alphaliner: Container Ship Charter Rates to Weaken in 2013. https://www.joc.com/comment/1601, [accessed on 18.12.2013].

[12] Pierre C. Is slow steaming a sustainable means of reducing $\mathrm{CO}_{2}$ emissions from container shipping? Transportation Research Part D 2011; 16:260-264.

[13] Alphaliner: Slow steaming absorbs capacity. http://www.transportjournal.com/en/home/news/artikeldetail/slow-steaming-absorbs-capacity.html, [accessed on 18.12.2013].

[14] Wärtsilä. Marine solutions (2 ${ }^{\text {nd }}$ ed.). Publication no: SPEN-DBAC136254; 2012.

[15] MAN Diesel \& Turbo. Marine engine IMO Tier II programme 2013. Publication no. 4510-0012-00ppr; 2013.

[16] MAN Diesel \& Turbo. Waste heat recovery system (WHRS) for reduction of fuel consumption, emissions and EEDI. Publication no. 2210-0136-01ppr; 2012.

[17] Rupp M. Green ships on the high seas. ABB Review 2007; 4: 58-61.

[18] Schmid H. Less emissions through waste heat recovery. In: Green ship technology conference, London, UK. Helsinki: Wärtsilä Corporation; 2004. 
[19] Brown D. Helping shipowners cut fuel bills with Wärtsilä low-speed engines. Wärtsilä Tech J: Maine/ InDetail 2009; 1: 34-37.

[20] MAN Diesel \& Turbo. SFOC optimization methods for MAN B\&W two-stroke IMO Tier II engines. Publication no. 5510-0099-00ppr; 2012.

[21] Kamal K, Hui C. A semi-experimental modeling approach for a large two-stroke marine diesel engine simulation. 27 $7^{\text {th }}$ CIMAC World Congress, Shanghai, China; 2013.

[22] Kyrtatos NP, Koumbarelis I. Performance prediction of next-generation slow speed diesel engines during ship manoeuvers. Trans IMarE 1994; 106(Part I): 1-26.

[23] Kyrtatos NP, Theodossopoulos P, Theotokatos G, Xiros N. Simulation of the overall ship propulsion plant for performance prediction and control. In Proceedings of the Conference on Advanced marine machinery systems with low pollution and high efficiency; 1999.

[24] Hountalas DT. Prediction of marine diesel engine performance under fault conditions. Appl Therm Eng 2000; 20: 1753-1783.

[25] Campora U, Figari M. Numerical simulation of ship propulsion transients and full scale validation. Pro IMechE, Part M: J Engineering for the Maritime Environment 2003; 217: 41-52.

[26] Livanos GA, Theotokatos G, Kyrtatos NP. Simulation of large marine two-stroke diesel engine operation during fire in the scavenging air receiver. J Marine Eng Technol 2003; 3: 9-16.

[27] Scappin F, Stefansson SH, Haglind F. Validation of a zero-dimensional model for prediction of NOx and engine performance for electronically controlled marine two-stroke diesel engines. Appl Therm Eng 2012; 37: 344-352.

[28] Woodward JB, Latorre RG. Modeling of diesel engine transient behavior in marine propulsion analysis. Tran Soc Nav Archit Mar Eng 1984; 92: 33-49.

[29] Hendrics E. Mean value modelling of large turbocharged two-stroke diesel engines. SAE technical paper no 890564; 1989.

[30] Chesse P, Chalet D, Tauzia X. Real-time performance simulation of marine diesel engines for the training of navy crews. Mar Technol 2004; 41(3): 95-101.

[31] Grimmelius H, Mesbahi E, Schulten P. The use of diesel engine simulation models in ship propulsion plant design and operation. In: Proceedings of the $25^{\text {th }}$ CIMAC world congress on combustion engine technology, Viena, Austria, paper no. 227; 2007.

[32] Theotokatos G. On the cycle mean value modelling of a large two-stroke marine diesel engine. Proc IMechE, Part M: J Engineering for the Maritime Environment 2010; 224: 193-205.

[33] Theotokatos G, Tzelepis V. A computational study on the performance and emission parameters mapping of a ship propulsion system. Proc IMechE, Part M: J Engineering for the Maritime Environment 2013; DOI: 10. 1177/1475090213498715.

[34] Xiros N. Robust control of diesel ship propulsion. Springer, Berlin; 2002.

[35] Hadef J, Colin G, Talon V, Chamaillard Y. New physics-based turbocharger data-maps extrapolation algorithms: validation on a spark-ignited engine. 2012 IFAC Workshop on Engine and Powertrain Control, Simulation and Modelling (ECOSM); 2012. 
[36] Jensen JP, Kristensen AF, Sorenson SC, Houbak N, Hendricks E. Mean value modeling of a small turbocharged diesel engine. SAE 910070; 1991.

[37] Guillaume M, Vincent T. Implementing turbomachinery physics into data map-based turbocharger models. SAE Int. J. Engines 2009; 2(1):211-229.

[38] Wayne RS. A method to control turbofan engine starting by varying compressor surge valve bleed. MSc thesis, Virginia Polytechnic Institute and State University; 2001.

[39] Ghorbanian K, Gholamrezaei M. An artificial neural network approach to compressor performance prediction. Applied Energy 2009; 86:1210-1221.

[40] Cortes O, Urquiza G, Hernandez JA. Optimization of operating conditions for compressor performance by means of neural network inverse. 2009; 86:2487-2493.

[41] Yu Y, Chen L, Sun F, Wu C. Neural-network based analysis and prediction of a compressor's characteristic performance map. Applied Energy 2007; 84:48-55.

[42] Kyrtatos N, Glaros S, Tzanos E, Hatzigrigoris S, Dalmyras F. Systematic evaluation of performance of VLCC engine, comparing service monitored data and thermodynamic model predictions. $27^{\text {th }}$ CIMAC World Congress, Shanghai, China; 2013.

[43] Watson N, Janota MS. Turbocharging the internal combustion engine. Macmillan. Basingstoke. Hampshire; 1982.

[44] Heywood JB. Internal combustion engines fundamentals. McGraw-Hill. New York; 1988.

[45] Rohsenow WM, Hartnett JP, Ganic E. Handbook of Heat Transfer Fundamentals, 2nd ed. McGraw-Hill. New York; 1985.

[46] Meier E. A simple method of calculation and matching turbochargers. Publication CH-T $120163 \mathrm{E}$. Brown Boveri \& Company Ltd. Baden. Switzerland; 1981.

[47] MAN Diesel \& Turbo. Computerized Engine Application System-Engine Room Dimensioning. http://apps.mandieselturbo.com/ceas/client/erd.aspx, [accessed on 18.12.2013].

[48] SAE. Turbocharger nomenclature and terminology. SAE standard, 1995b.

[49] Munson BR, Young DF, Okiishi TH, Huebsch WW. Fundamentals of fluid mechanics $6^{\text {th }}$ edition; 2009.

[50] Dehner R, Selamet A, Keller Ph, Becker M., Fink DA. Simulation of Mild Surge in a Turbocharger Compression System; 2010, SAE Int. J. Engines, Volume 3, Issue 2, 197-212.

[51] MAN Diesel \& Turbo. MAN B\&W K98ME-C6 project guide: electronically controlled two-stroke engines, $5^{\text {th }}$ edition; 2009. 


\section{Nomenclature}

A area $\left(\mathrm{m}^{2}\right)$

BMEP brake mean effective pressure (bar)

BSFC brake specific fuel consumption $(\mathrm{g} / \mathrm{kW} \mathrm{h})$

$c_{d} \quad$ discharge coefficient

$c_{V} \quad$ specific heat at constant volume $(\mathrm{J} / \mathrm{kg} \mathrm{K})$

D deviation

$h \quad$ specific enthalpy $(\mathrm{J} / \mathrm{kg})$

$H_{L} \quad$ fuel power heating value $(\mathrm{J} / \mathrm{kg})$

I polar moment of inertia $\left(\mathrm{kg} \mathrm{m}^{2}\right)$

$k \quad$ coefficients

$m \quad$ mass $(\mathrm{kg})$

$\dot{m} \quad$ mass flow rate $(\mathrm{kg} / \mathrm{s})$

$M_{\text {inl }} \quad$ compressor impeller tip Mach number

$N \quad$ rotational speed (r/min)

$p \quad$ pressure $(\mathrm{Pa})$

pr pressure ratio

$Q \quad$ torque $(\mathrm{N} \mathrm{m})$

$\dot{Q} \quad$ heat transfer rate (W)

$r_{C} \quad$ compressor impeller radius (m)

$R \quad$ gas constant $(\mathrm{J} / \mathrm{kg} \mathrm{K})$

$t \quad$ time (s)

$T \quad$ temperature (K)

$u \quad$ specific internal energy $(\mathrm{J} / \mathrm{kg})$

$U_{C} \quad$ compressor blade tip velocity $(\mathrm{m} / \mathrm{s})$

$\dot{V} \quad$ volumetric flow rate $\left(\mathrm{m}^{3} / \mathrm{s}\right)$

$z_{c y l} \quad$ number of engine cylinders

Greek symbols

$\gamma \quad$ ratio of specific heats

$\Delta \phi_{c y} \quad$ engine cycle duration (deg)

$\Gamma_{C} \quad$ non-dimensional torque coefficient

$\zeta \quad$ proportion of the chemical energy

of the fuel contained in the exhaust gas

$\eta \quad$ efficiency

$\rho \quad$ density $\left(\mathrm{kg} / \mathrm{m}^{3}\right)$

$\phi \quad$ crank angle (deg)

$\varphi \quad$ non-dimensional flow coefficient

$\Psi \quad$ non-dimensional isentropic head coefficient
Subscripts

$a m b \quad$ ambient

$A C \quad$ air cooler

$A F \quad$ air filter

$B L \quad$ blower

comb combustion

cor corrected

cyl cylinder

C compressor

d downstream

ep exhaust pipe

eq equivalent

ev exhaust valve

ew entrained water

$E \quad$ engine

$E R \quad$ exhaust receiver

$f \quad$ fuel

$i \quad$ isentropic

in inlet

out outlet

$P \quad$ propeller

ref reference

sp scavenging ports

SC scavenging receiver

Sh shafting system

$T \quad$ turbine

TC turbocharger

U upstream

Abbreviations

ISO International Organization for Standardization

MCR maximum continuous rating

MVEM mean value engine modelling 


\section{List of figure captions}

Fig. 1. Large containership propulsion engine model implemented in MATLAB/Simulink environment

Fig. 2. Compressor performance map

Fig. 3. Fitted surface interrelating non-dimensional flow coefficient, non-dimensional isentropic head coefficient and Mach number for zone 3

Fig. 4. Comparison between available compressor map curves and the respective similarity laws results

Fig. 5. Extrapolation/interpolation of compressor performance map

Fig. 6. Non-dimensional torque coefficient vs. non-dimensional flow coefficient data and applied linear fit for zone 2 speed curves

Fig. 7. Compressor maximum isentropic efficiency as a function of corrected speed

Fig. 8. Prediction of compressor isentropic efficiency at various corrected speed values

Fig. 9. Steady state simulation results and comparison with shop trials data

Fig. 10. Steady state simulation results for the cases of blowers activation and one turbocharger unit cut-out

Fig. 11. Simulation results for the engine transient operation with load changes $45 \%-25 \%-40 \%$

Fig. 12. Compressor operating points trajectory for the engine transient operation with load changes $45 \%-25 \%-40 \%$

Fig. 13. Compressor operating points trajectory for the engine transient operation with load changes $45 \%-15 \%$

Fig. 14. Simulation results for the engine transient operation with load changes $45 \%-15 \%$

\section{List of table captions}

Table 1 MAN B\&W 12K98ME-C engine parameters

Table 2 Steady state simulation results, comparison with shop trials data 
Table 1 MAN B\&W 12K98ME-C engine parameters

\begin{tabular}{cc}
\hline Bore & $980 \mathrm{~mm}$ \\
Stroke & $2400 \mathrm{~mm}$ \\
Number of cylinders & 12 \\
Brake power at MCR & $68500 \mathrm{~kW}$ \\
Engine speed at MCR & $104 \mathrm{r} / \mathrm{min}$ \\
BMEP at MCR & $18.2 \mathrm{bar}$ \\
Turbocharger units & 4 x MHI MET83 \\
\hline
\end{tabular}

Table 2 Steady state simulation results, comparison with shop trials data

\begin{tabular}{lccccc}
\hline Engine load (\% MCR) & 100 & \multicolumn{1}{l}{85} & 75 & 50 & 25 \\
\cline { 2 - 6 } & Error $(\%)$ & & & \\
\hline Brake power & 0.80 & -0.96 & -1.04 & -0.85 & -0.94 \\
BSFC & -0.17 & -0.21 & 0.06 & 0.05 & 0.06 \\
BMEP & 0.18 & -1.01 & -1.09 & -0.86 & -0.92 \\
Turbocharger speed & 0.01 & -0.32 & 0.00 & -0.46 & -3.51 \\
Scavenging air receiver pressure & -3.87 & -4.01 & -4.40 & -2.08 & -2.39 \\
Exhaust gas receiver pressure & 1.10 & -0.97 & 0.03 & 0.48 & -1.26 \\
Scavenging air receiver temperature & 1.09 & 0.39 & 1.00 & 0.42 & -0.33 \\
Exhaust gas receiver temperature & 3.88 & 2.08 & 2.55 & 1.59 & 1.35 \\
Exhaust gas temperature after turbocharger & 0.40 & -2.44 & -1.72 & -2.42 & -4.40 \\
Fuel mass flow rate & 0.63 & -1.17 & -0.98 & -0.79 & 1.0 \\
Mechanical efficiency & 0.16 & -0.04 & -0.04 & -0.11 & 0.10 \\
\hline
\end{tabular}




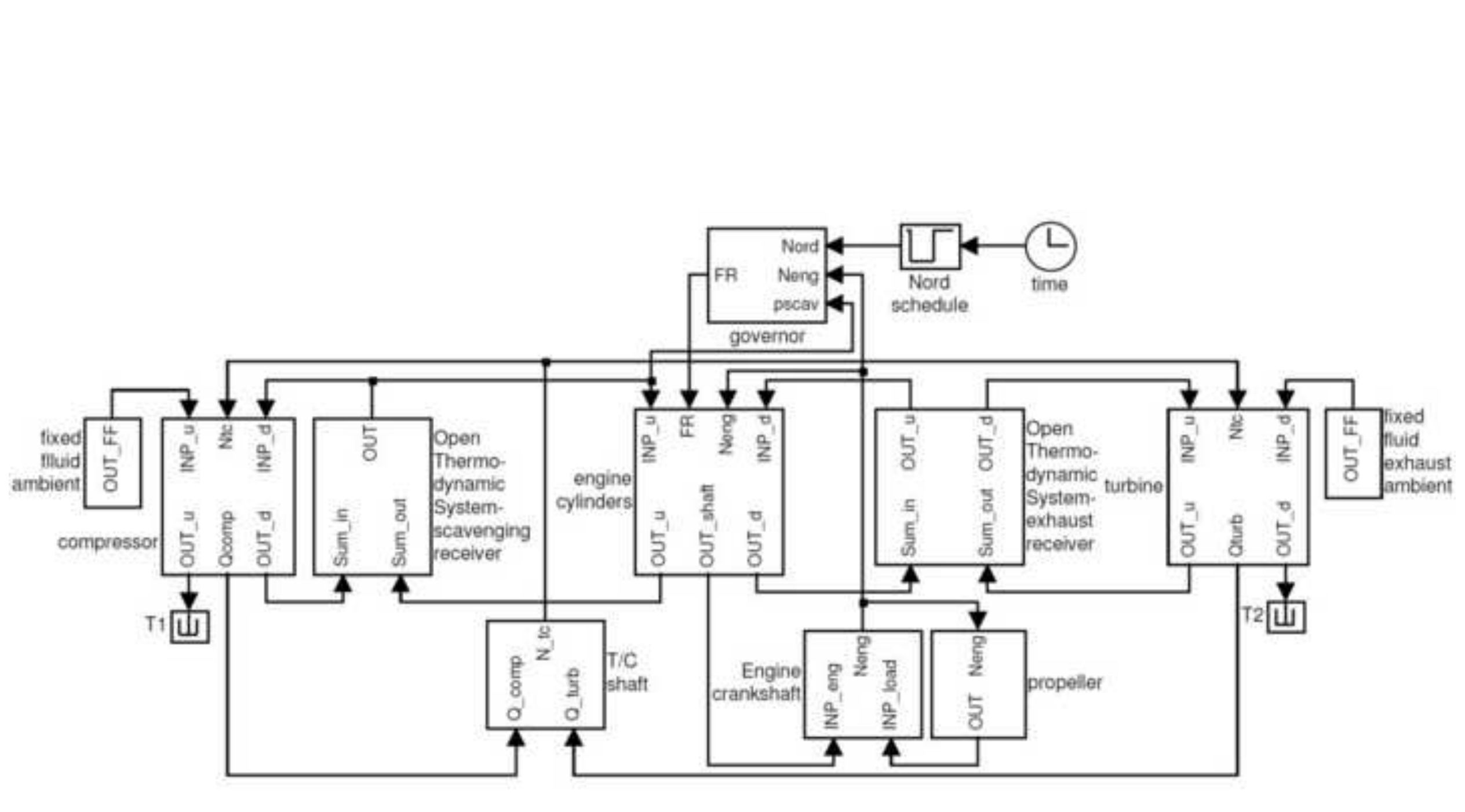




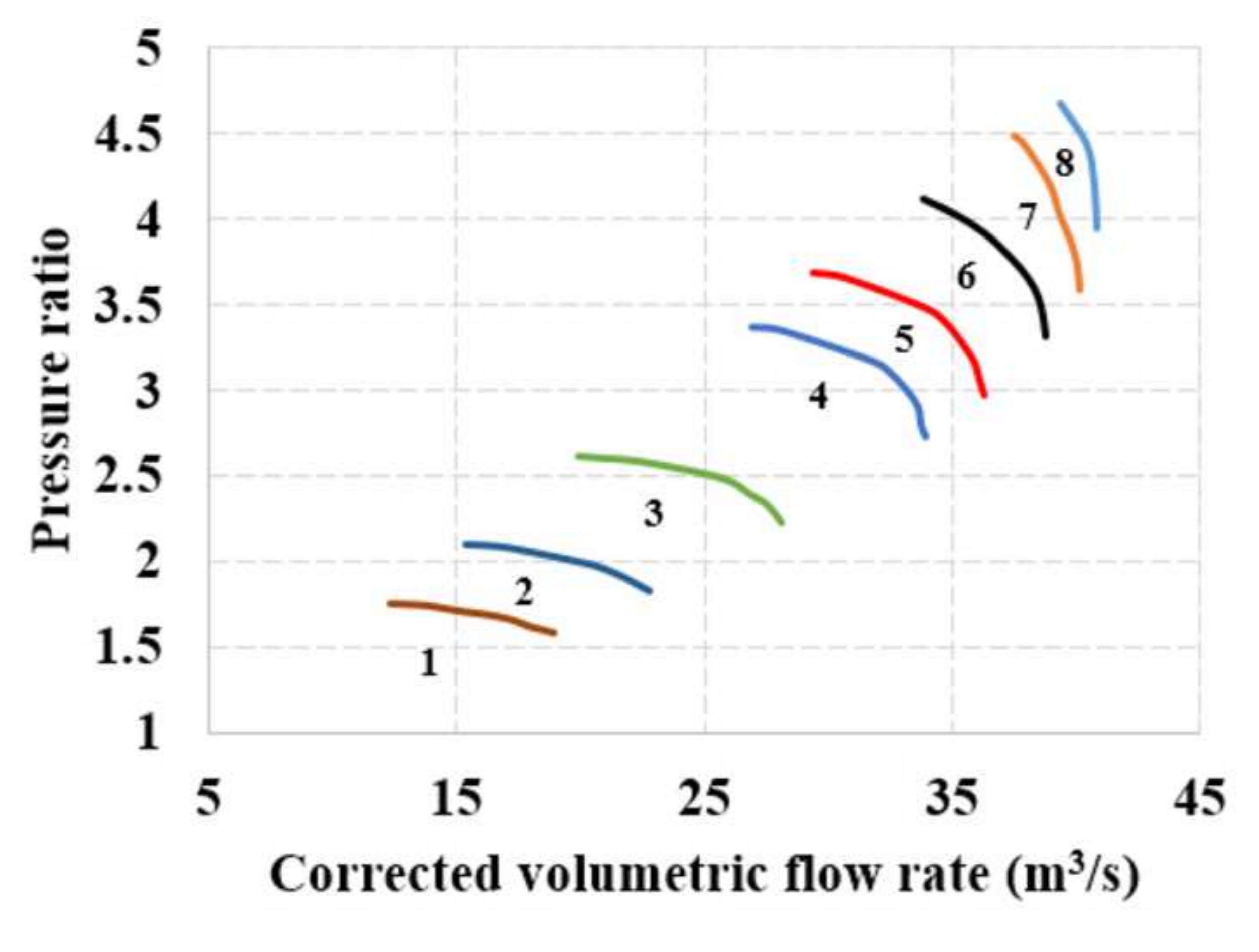

.
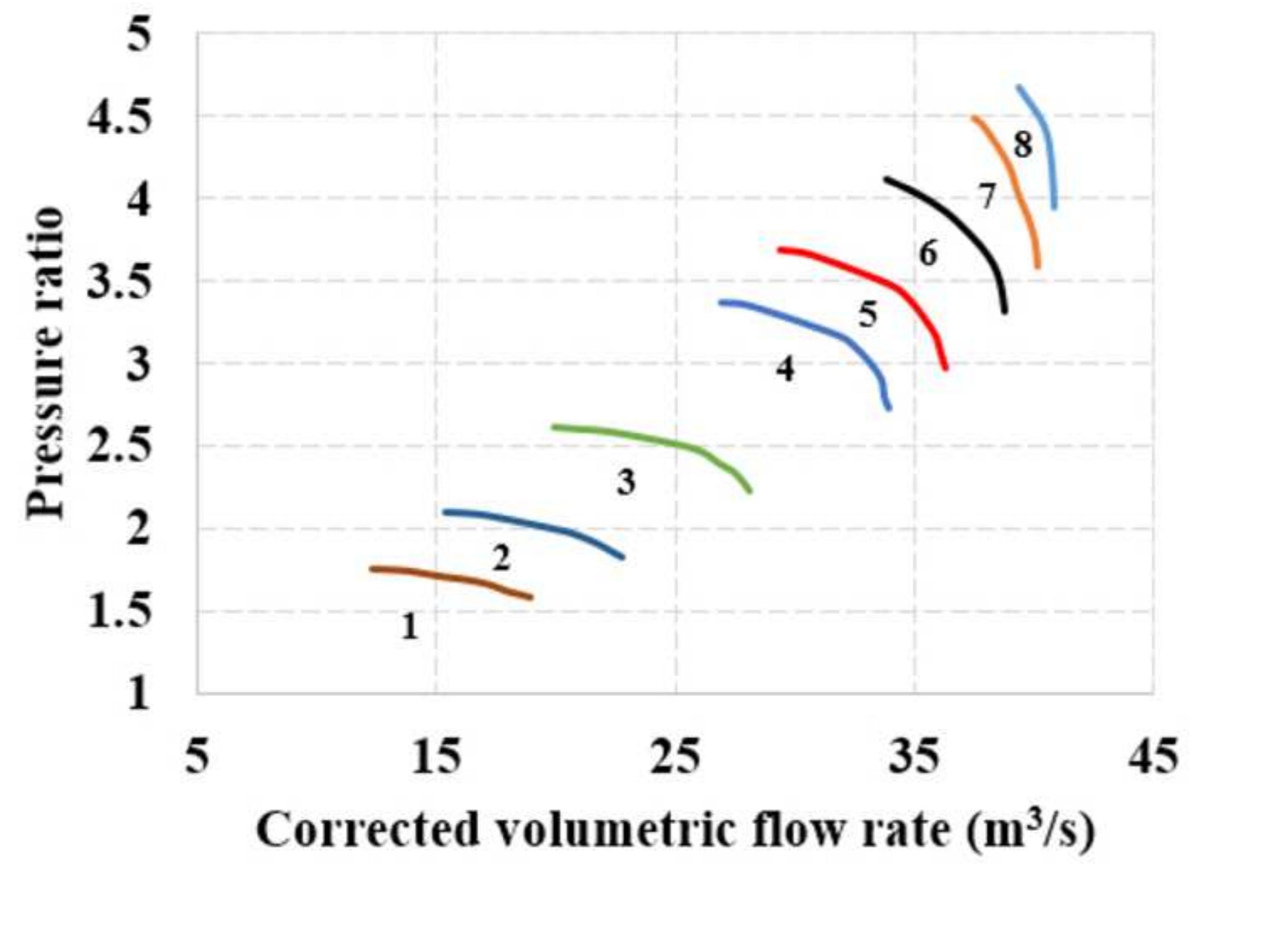

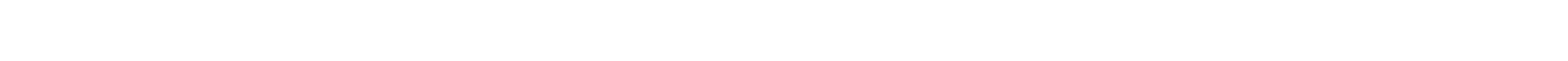

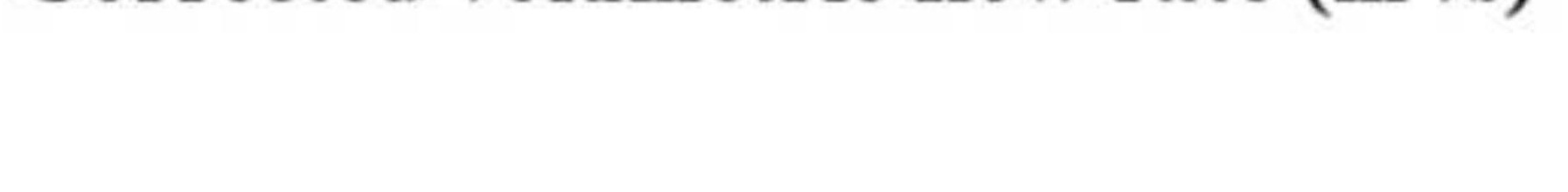

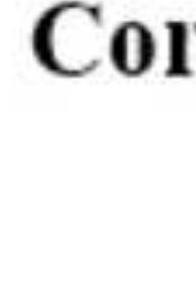




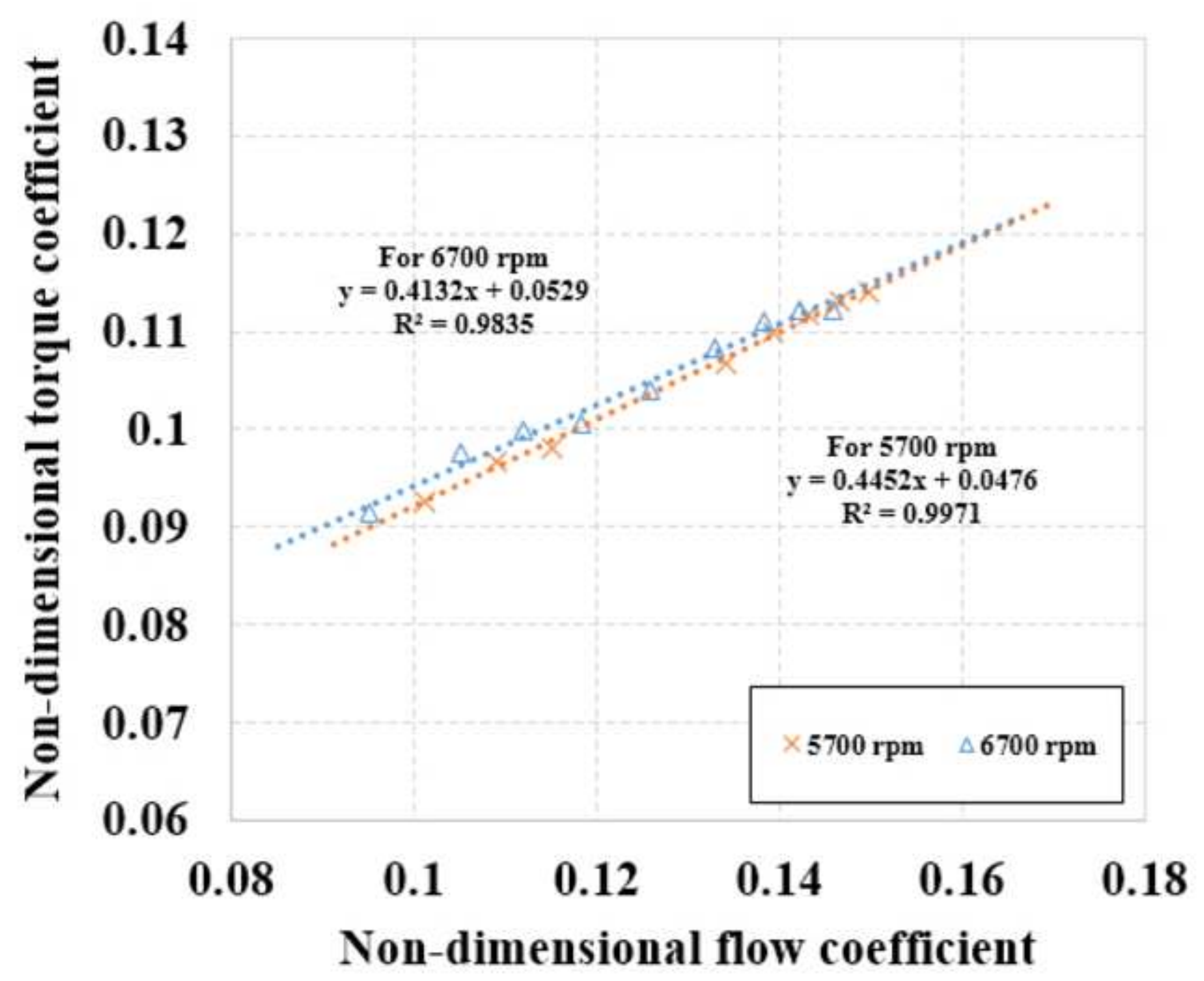




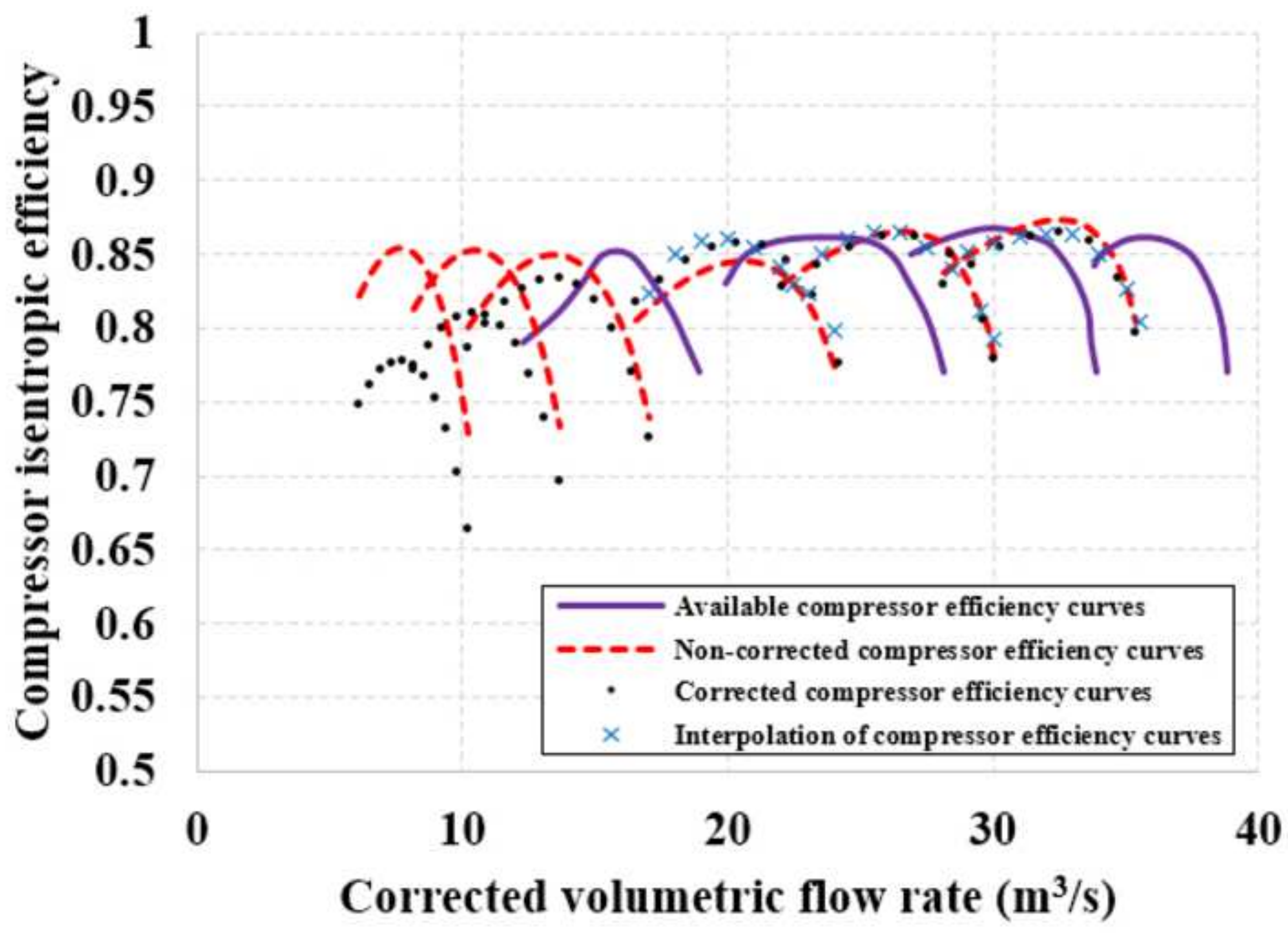



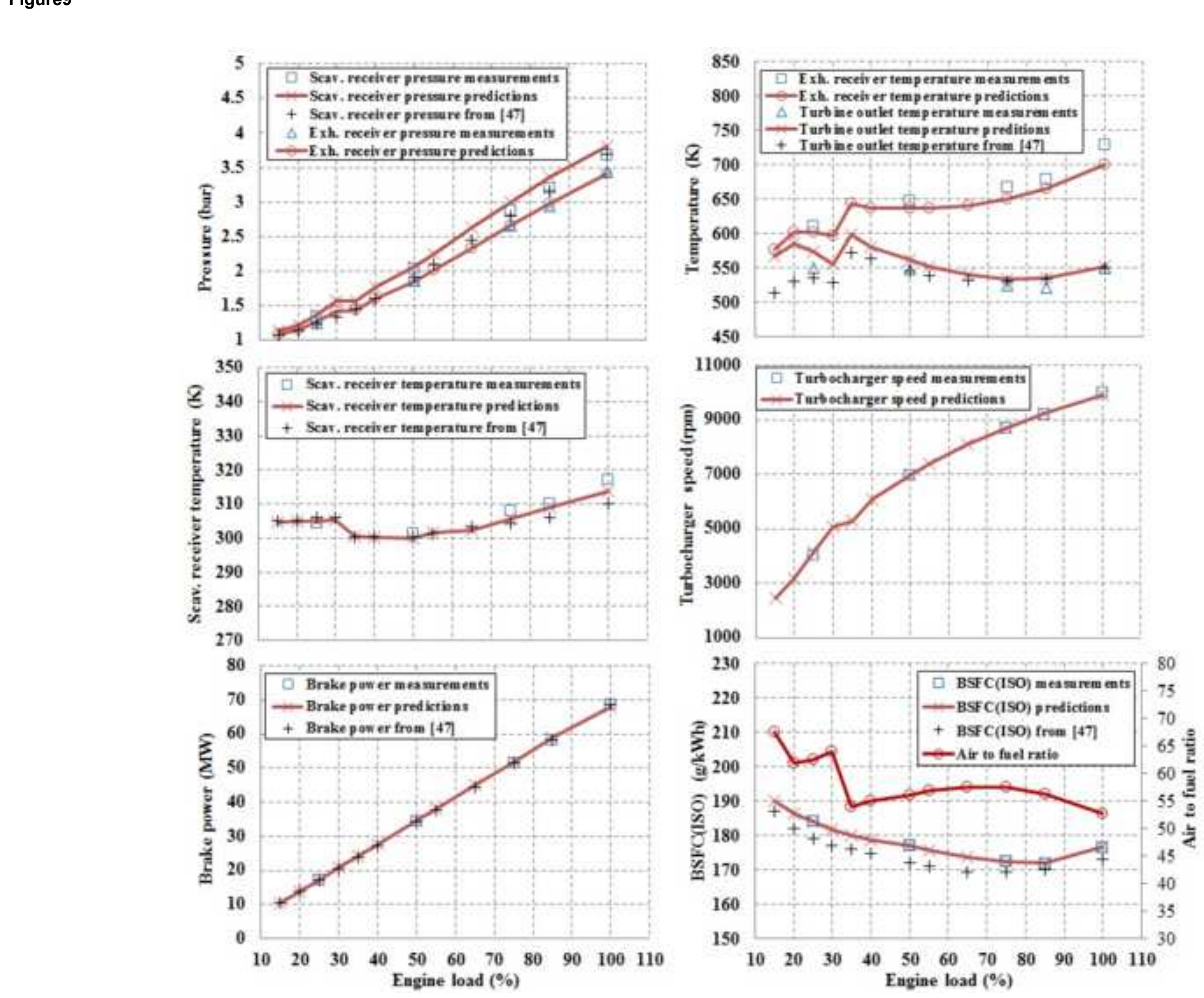

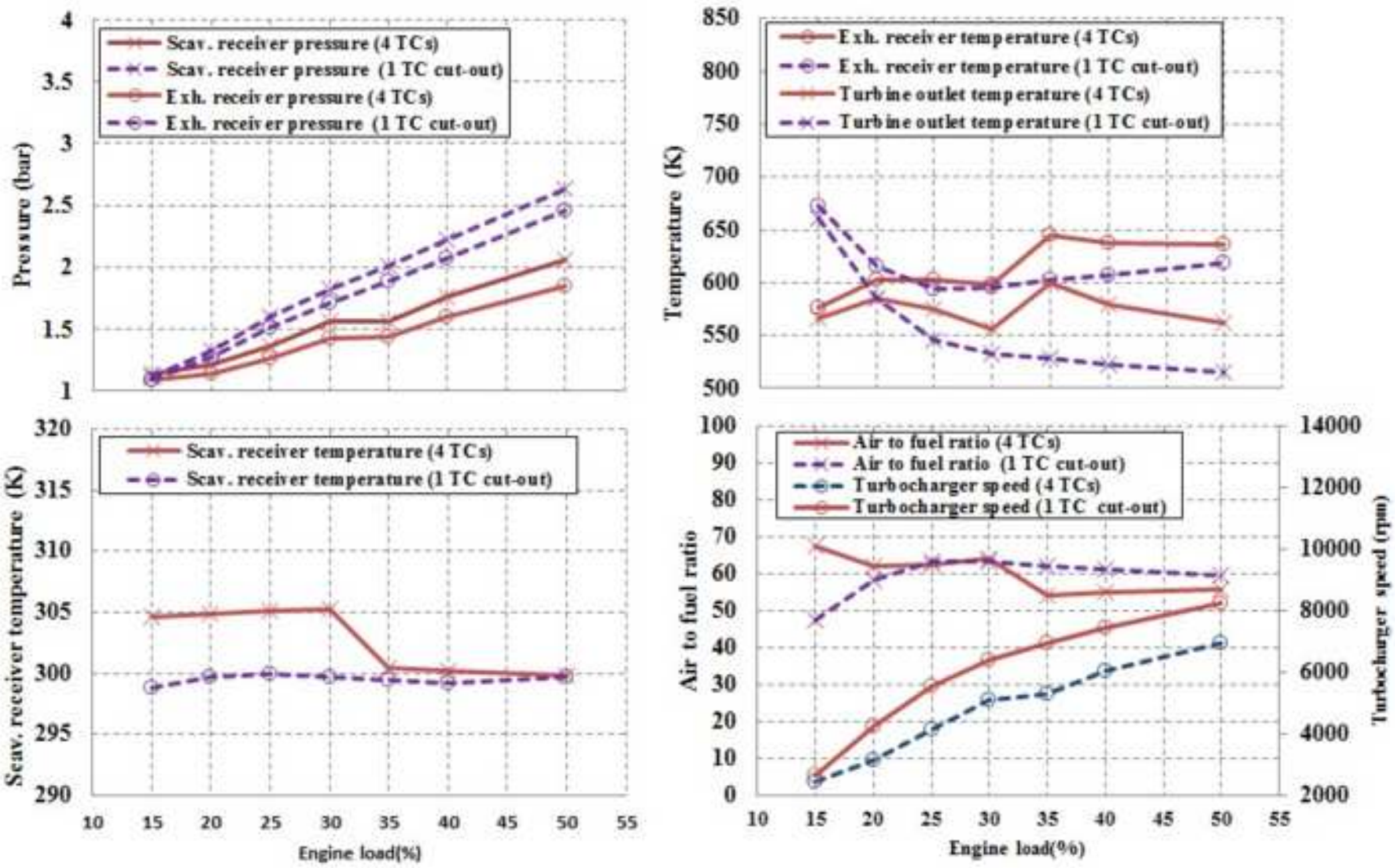

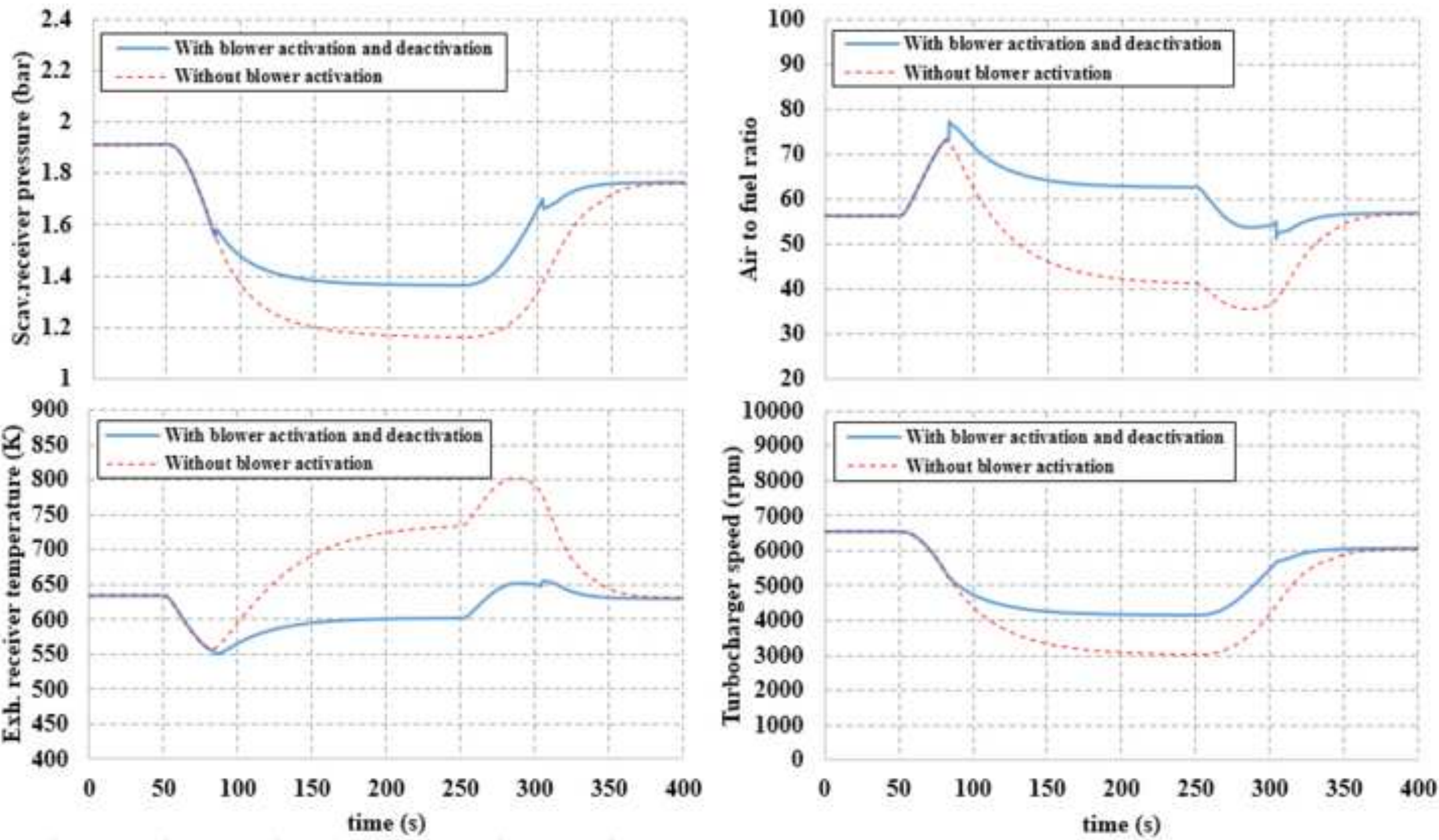


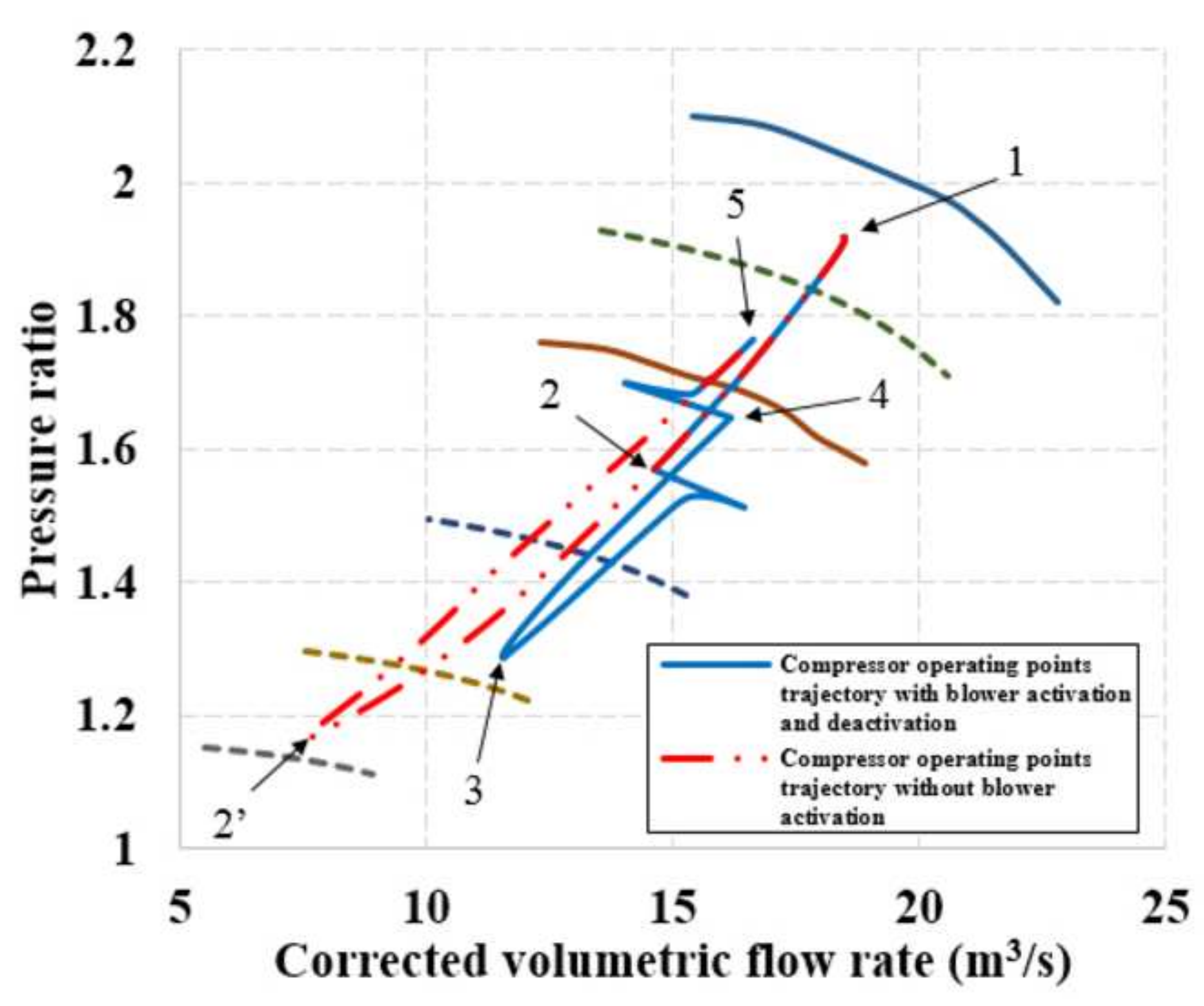




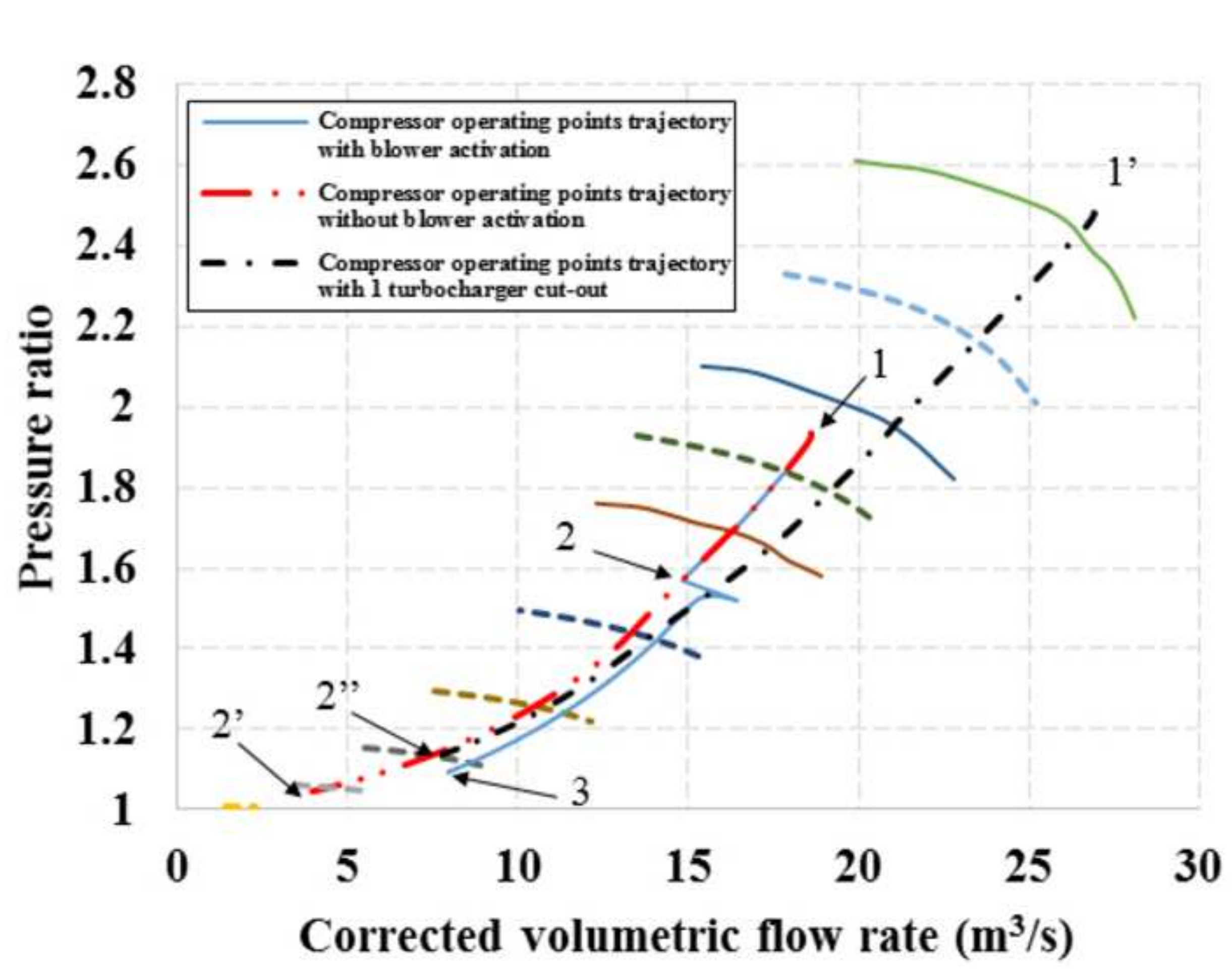

.

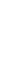
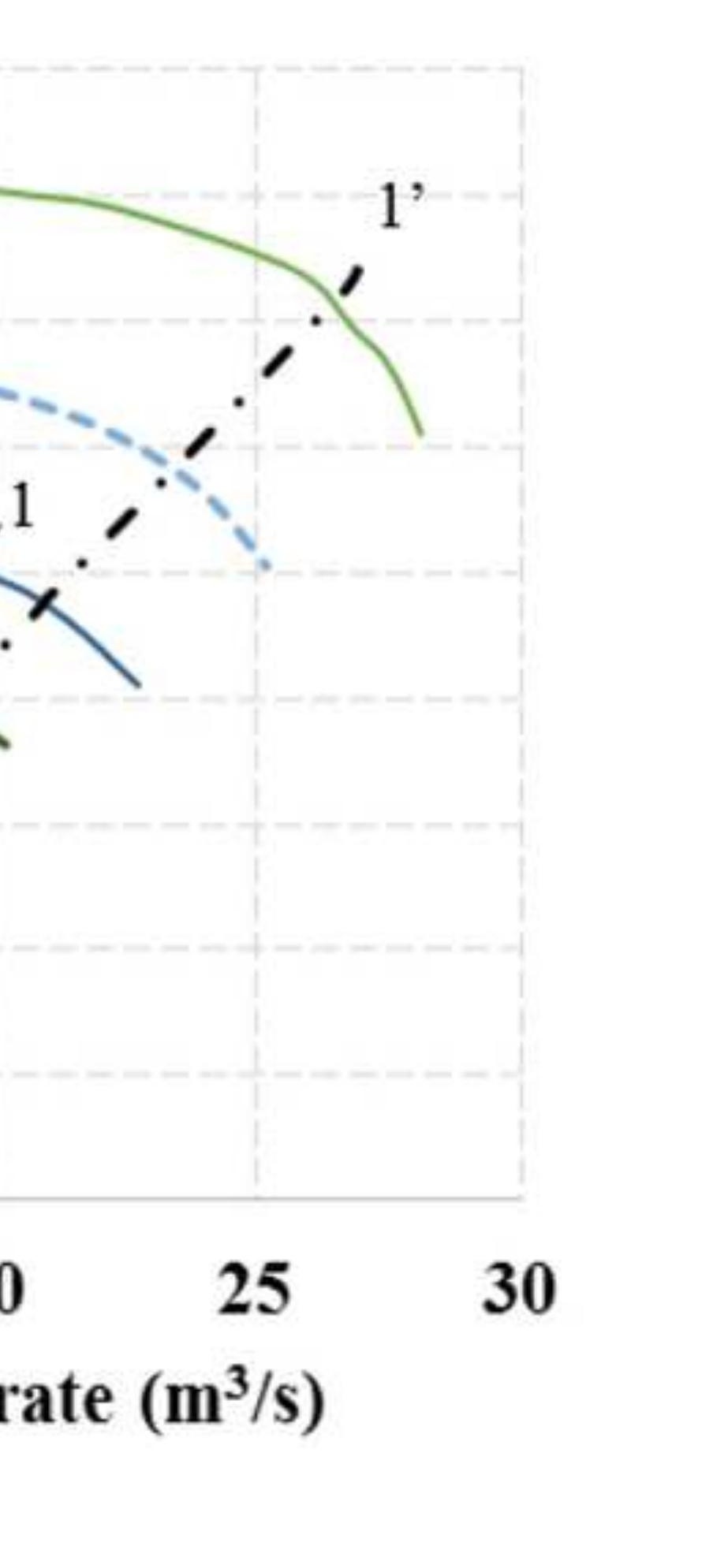

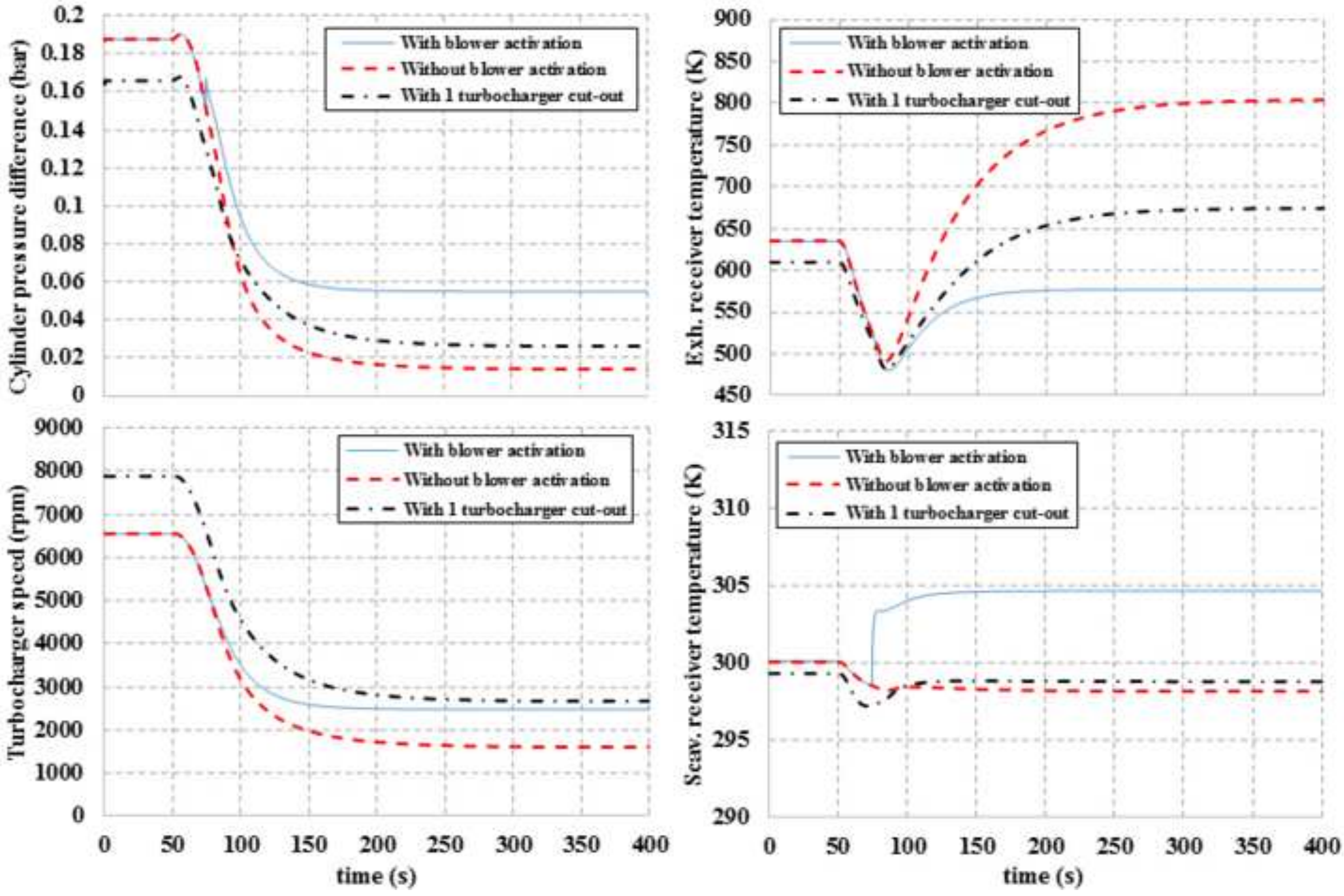